\title{
AN EXPERIMENTAL STUDY OF THE CONSCIOUS ATTITUDES OF CERTAINTY AND UNCERTAINTY
}

\author{
By John Trumbell Metcalf, Ph.D. \\ Instructor in Psychology \\ Snith College
}

The object of the present investigation is an analysis of the conscions attitude (Bezusstseinslage) on the motor side. The effort is made to determine whether certain regular forms of bodily reaction accompany the suljective attitude of certainty, and whether with changes in subjective attitude there are corresponding changes in the forms of such reaction. The subject is given a task which he carries through in response to certain instructions. The motor processes immediately involved in carrying through this reaction to the instructions are recorded by the apparatus, and at the end of each experiment the subject gives a complete introspective report. These two records, the objective record of the form of the reaction and the introspective record of the conscious processes experienced during the reaction, are examined together to see if there is any correspondence between them. The tasks chosen for the investigation consist in the making of drawing movements with the hand out of sight. The apparatus gives records of the accuracy of these movements, and of all changes in rate and pressure which occur during the process. Variations are introduced to determine whether by changing the instructions in such a way as to modify the objective form of the reaction a corresponding change may be produced in the subjective attitude.

The conscious attitude has come to hold a very important place in psychological theory, and a good deal of work has been directed toward analyzing it by the introspective method. Yet, to the writer's knowledge, no attempt has been made to attack it on the motor side. The present investigation attempts this, its object being to find out whether the introspectively given attitude of certainty involves a definite form of motor reaction on the part of the subject, and a change in the attitude a change in the form of such reaction. The method used is an extension of that which has already been employed in the investigation of the relation between motor processes and consciousness. Judd (2) has shown that the character of perception and attention is closely connected with motor processes. The present work follows the 
same method, extending it to that phase of consciousness which experimenters in the field of the higher thought processes have called the "Bein'isstseinslage" or conscious attitude. This investigation is, therefore, more closely related to the experimental work on the relation between movement and consciousness than it is to the almost exclusively introspective experimental investigations of the higher thought processes.

The first requisite in an investigation of this sort is a motor process, simple enough to be measured objectively, and yet sufficiently difficult of performance to yield the necessary richness of introspective data. The making of simple drawing movements with the hand hidden from sight was chosen as the task. These drawing movements were measured by the apparatus, and after each drawing full introspections were given by the subject and taken down by the experimenter. The drawings were made in response to certain instructions, and in the course of carrying out the process various attitudes appeared, as reported in the introspections. Now if there is any relation between attitude and motor processes in general the attitudes reported here must be connected with the particular motor processes measured by the apparatus, because both attitude and the processes measured come of necessity in response to the instructions. In other words, the motor processes, i. e., the drawing movements, measured by our apparatus are necessarily involved in carrying out the instructions, and are therefore particularly relevant to any attitudes consequent upon the instructions.

The apparatus for measuring the drawing movements was that used by Freeman in his analysis of writing movements (I). The two cuts of the apparatus which appear there are reprinted here (Figs. I and 2).

This apparatus yields three objective records of the drawing movements. In the first place there is the actual drawing made by the subject upon the primary sheet. The task was usually the copying of a simple geometrical figure-the "model." Thus when the drawing is measured for straightness of lines, length of lines, size of angles, etc., and these measurements compared with the corresponding measurements of the model, a record of 


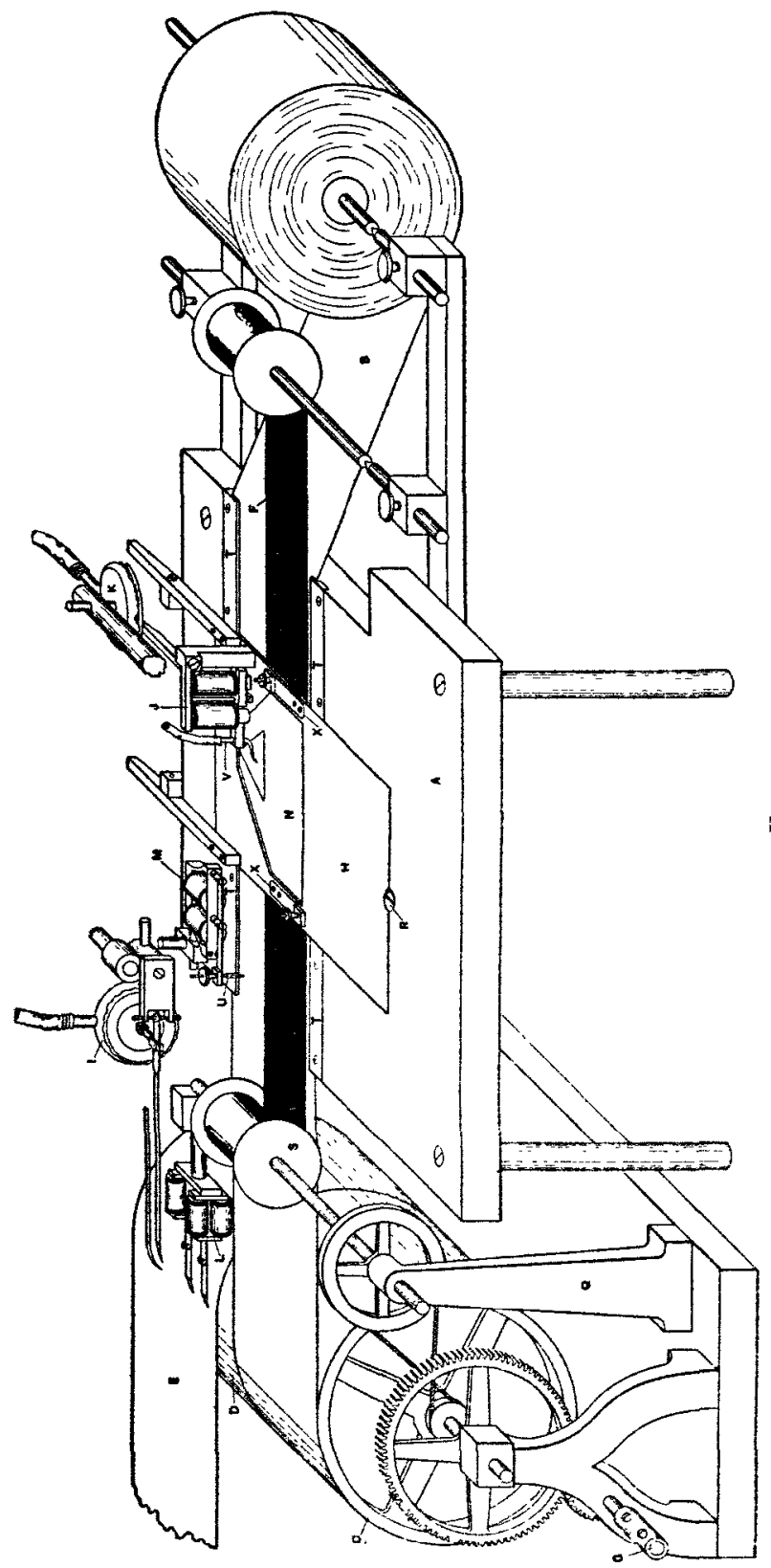

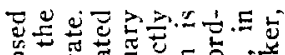

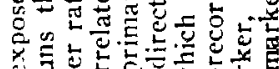

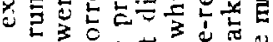

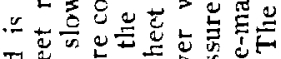

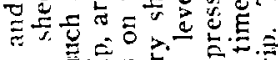
$\therefore$ EE त

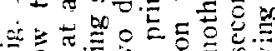

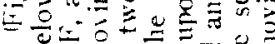

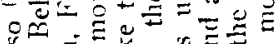

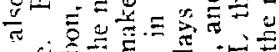
(1)

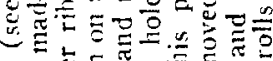
$=0$.

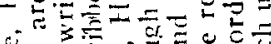

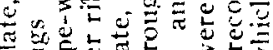

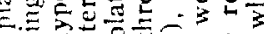

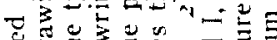

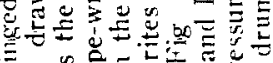

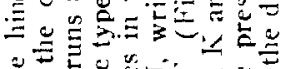

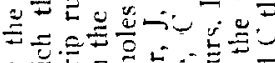

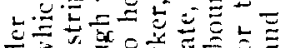
-

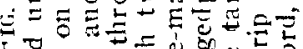

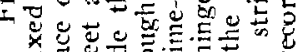
\& 은

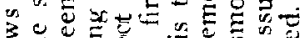
政

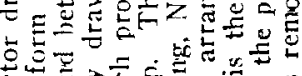

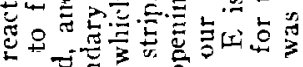

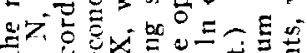

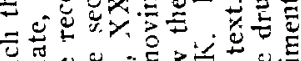

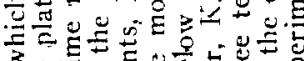

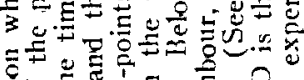

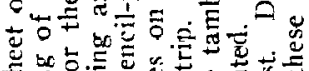

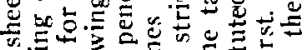
$\rightarrow x_{0}$ 等 ․ㅡㄹ c.

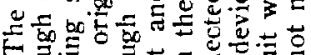

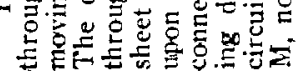




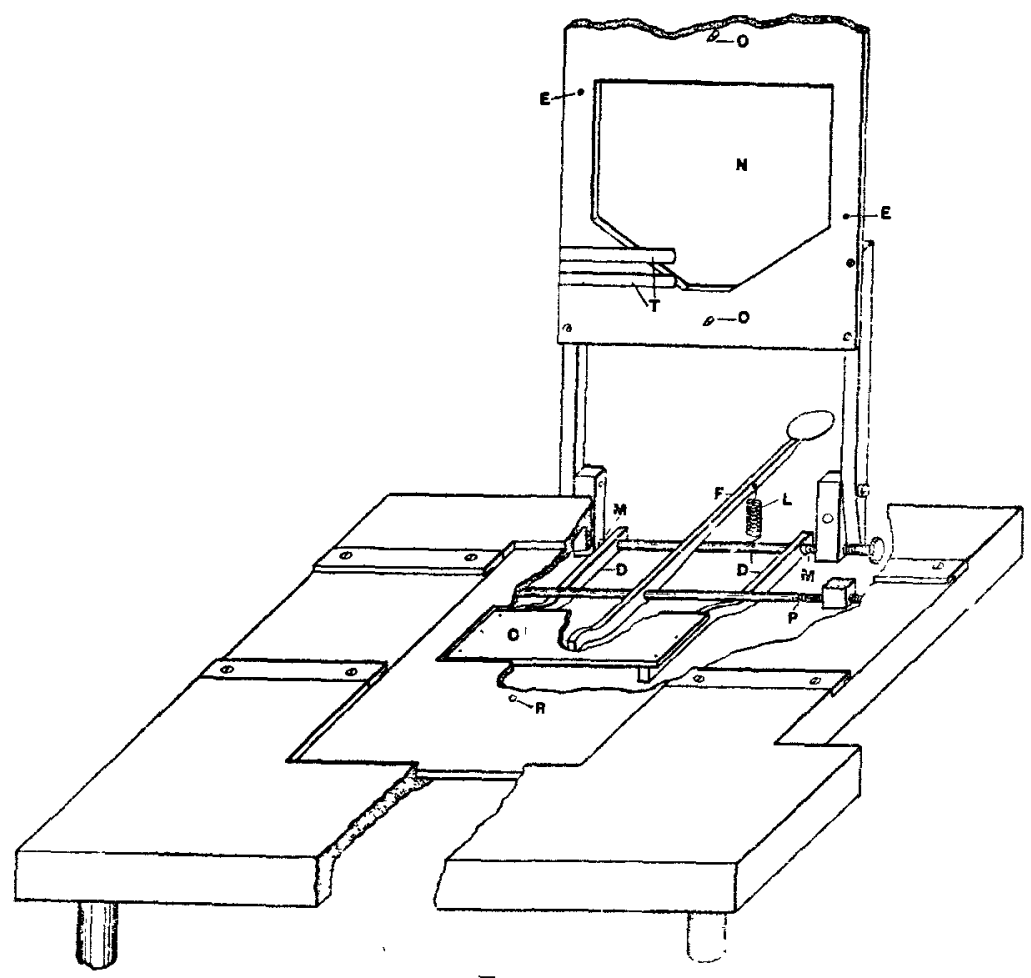

FIG. 2.

accuracy is obtained. In the second place, the apparatus gives a time record for the whole drawing or any part of it. As the subject draws upon the primary sheet his drawing is registered through the typewriter ribbon upon the moving strip. This gives a record of the whole drawing spread out under a standard timeline traced by the first marker. By correlating this with the original drawing in the manner described by Freeman, it is possible to follow the details of time changes throughout. In the third place, the apparatus gives a record of pressure. The drawings are made above the hinged plate which sinks slightly when pressure is exerted upon it. This movement of the plate, much magnified, is communicated to a pointer which traces a curve upon a smoked strip. In this way all changes in the pressure exerted by the subject in drawing are registered. This pressure 
record is correlated with the recurds of time and accuracy through a second standard time-line traced upon the smoked strip by a second marker in circuit with the other. The time is given by a Kronecker Interrupter located in another room, marking tenths of a second. Three records are, therefore, obtained from each drawing movement, showing its accuracy, the rate of drawing throughout, and synchronous changes in pressure.

Several changes were, however, made in Freeman's apparatus. A finely-pointed lead-pencil was used in place of his capillary pen for the time-record on the moving strip. An eiectric motor was used to drive the apparatus. This motor was encased in a wooden box heavily lined with felt to shut in the noise. Its speed was reduced through a worm-gear mounted in a standard on the top of the box. The drum, C, Fig. I, was turned by a string-belt from the driving-wheel of the worm-gear. This method lacks only one of the advantages of the original arrangement. It is not now possible to start the apparatus at full speed, as could be done when the friction clutch was used. This proved to be no detriment, however, as it took the apparatus only a very short time-about two seconds-to develop its maximum speed. This time was just about the interval the experimenter allowed between the starting of the motor and the giving of the signal to begin drawing. The chief advantage in using the motor is that it eliminates a great deal of distracting noise.

A third and more important change in the original apparatus was the substitution of a new pressure-recording device for the tambours. The tambours were used in the first practice series, and were found unsatisfactory for the purposes of this experiment. The pressure in a drawing movement is usually less in amount and more gradual in its changes than that in a writing movement. This calls for a recording device which is more sensitive and which magnifies the record to a greater degree. There is always a stretch to the rubber of the tambours and to the walls of the connecting-tube. The movements are thus softened down so that some of their characteristics are lost. The simple device used in these experiments does away with this deficiency, as well as satisfying the other conditions. 


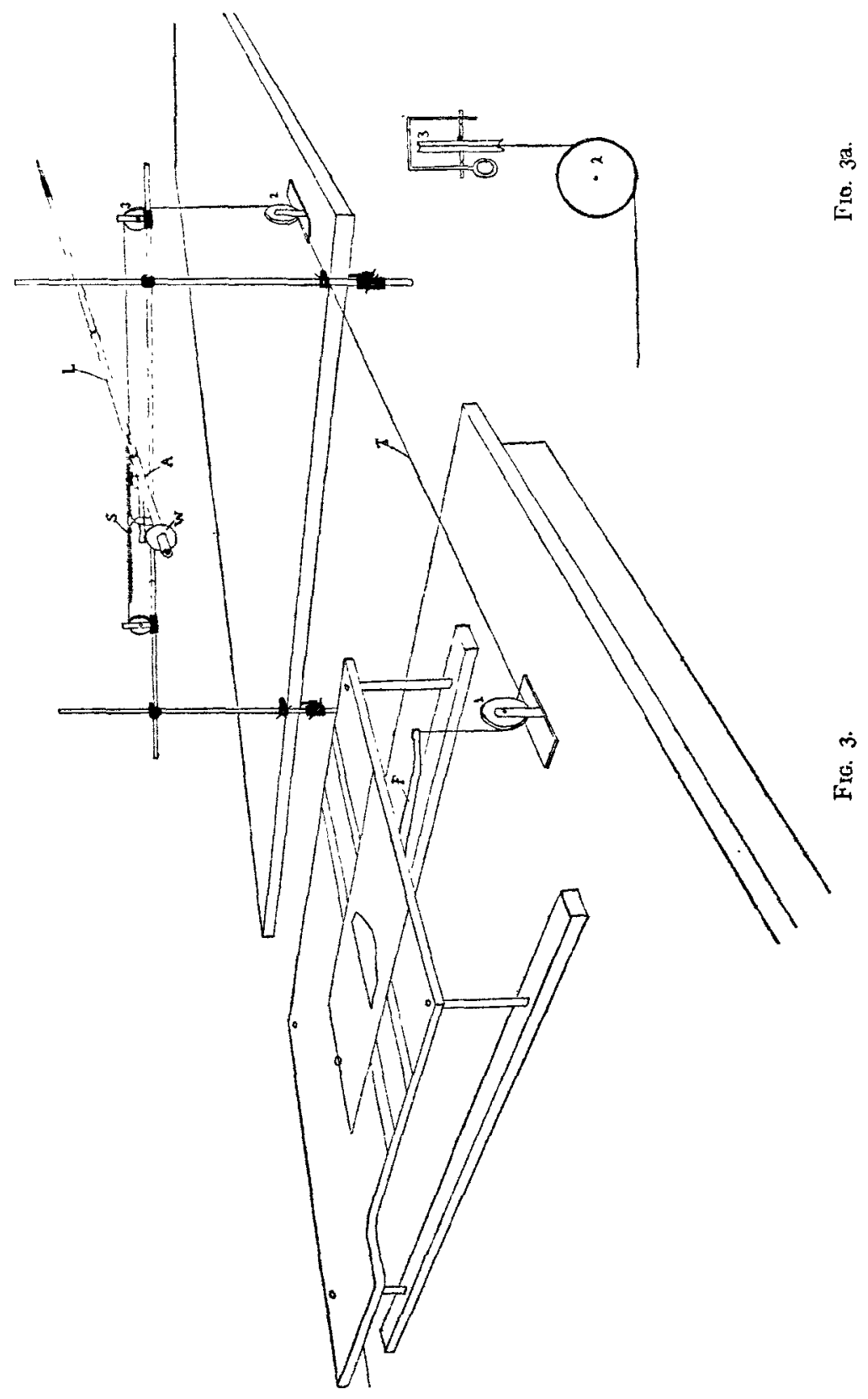


The two tambours, I and K, Fig. I, were removed, as was also the metal disc on the end of the lever, F, Fig. 2. A new recording-pointer was made. As this pointer was of considerable length, the drum D, Fig. I, over which the smoked strip runs, had to be moved away from the rest of the apparatus. It was accordingly placed about a meter away from the drum, $\mathrm{C}$, and run by a string-belt from a wheel on the axle of the drum $\mathrm{C}$, to a wheel of the same size on its orn axle. The marker, L, Fig. 1 , was held by a special standard which stood on the table. The new recording-pointer was made of a thin piece of bamboo, $\mathrm{L}$, Fig. 3, $60 \mathrm{~cm}$. in length. At the recording end it was supplied with a metal recording-point. Near the other end it was pierced by an axis, A, which was then mounted in bearings. The movements of the lever, F, Fig. 2, were communicated to the recording-pointer by means of a thread running over a system of wheels. These wheels were made of wood and were supplied with fixed axles mounted on bearings, friction being thus reduced to a minimum. Fig. 3 shows how the movements of the lever, F, are communicated to the recording-pointer, $\mathrm{L}$, which is at right angles to it and on a different level. The wheels over which the thread, T, runs are numbered $\mathrm{I}, 2$, and 3 . An end view of the arrangement of wheels 2 and 3 is given in Fig. 3 a. The thread was attached to the recording-pointer between the axis and the point $-9 \mathrm{~cm}$. from the axis and $42 \mathrm{~cm}$. from the point. At this place too, on the other side of the pointer, there was attached a long fine spring, $S$, the tension of which could be readily and delicately regulated. A small round weight, W, Fig. 3, with a circular hole in the middle, was placed over the short end of the recording-pointer to make its weight equal on either side of the axis.

Another addition to the apparatus was the screen for cutting off the subject's view of his hand as he drew. The screen was of grey card-board, held in place by means of clamps, which were in turn held by uprights clamped to the large surface, A, Fig. I. Another large screen of black card-board was used to cut off the subject's view of the pressure apparatus.

The marker, M, Fig. I, used by Freeman to record the giving 
of the signal in reaction experiments was not needed for our purposes, and was removed. A slight change was made in the arrangement of the marker, J. Instead of its being fastened to the plate, $\mathrm{H}$, it was held just above it in a clamp attached to a rod running from one of the uprights holding the screen. To this same upright, higher up, were also attached the rod and clamp for holding the card on which the model was drawn. The models were drawn in black on white cards $12.5 \mathrm{~cm} . \times 7.5 \mathrm{~cm}$. The figures used are illustrated in Fig. 4, and will be described in detail in the statements of the individual series. The method of measurement adopted in each case will also be described there.

The apparatus was run more slowly than in Freeman's experiments, drawing movements being made more slowly and with more gradual changes in speed and pressure than writing movements. Moreover, the experiment is of such a character that it does not demand as minute an analysis of the movements as did Freeman's. Accordingly the apparatus was run just fast enough so that the records could be read in Iooths of a second.

In an investigation of this sort another requisite is that the subjects give full introspections. In our experiments they were instructed to tell after each experiment everything that had gone on in consciousness from the giving of the signal to begin the drawing to the end of the drawing. The introspective reports were not confined to this period, however, and general remarks made by the subject were also accepted by the experimenter though they were not given the same weight as the introspective report. Sometimes the experimenter increased the fulness of the report by appropriate questions, but care was taken that these should not be suggestive. Those who served as subjects were all trained psychologists. They were Professors Angier (A.) and Cameron (C.), Dr. E. P. Frost (F.), Instructor in Psychology, and Mr. S. L. Reed (R.), a graduate student in Psychology. To these men I am indebted not only for the large amount of time they have given me as subjects, but also for many pieces of helpful criticism and advice. The subjects were kept as naive as possible. With the exception of $A$, none of them knew the purpose of the experiment, or anything about the results. A. 
knew the purpose of the experiment, having himself suggested the problem, but he entered upon the investigation unconscious of any bias, and without anticipating any of the results. He was also kept in ignorance of his own results, though he did examine some of the results obtained from other subjects in cases where their task had been different from his own.

The method of procedure was as follows. Before each experiment the model was placed in its holder. The subject seated himself before the apparatus, took the pencil, and placed his hand under the screen ready to draw. He then received his instructions. The experimenter, after a preliminary "Ready" signal, started the motor and the two time-markers and, finally, gave the signal "Now" for the subject to begin drawing. This succession- "Ready," starting of apparatus, and "Now"-was not carried through in connection with any time-regulating mechanism, but the intervals were kept as nearly equal and constant as possible. As soon as the drawing was finished, the experimenter stopped the apparatus and took down the subject's introspections.

The instructions in these experiments, though not given in a stereotyped formula each time, were nevertheless definite and as brief as possible. At the beginning of a series the experimenter described to the subject in exact terms how the figure was to be drawn, i. e., that he was to begin at a certain definite point, proceed in a certain direction, and make his drawing as nearly like the model in size and form as he could. These instructions were briefly repeated for each drawing of the series. In all the earlier experiments no instructions were given concerning the rate of drawing or the pressure to be exerted, since variations in these objective factors, rate and pressure, were to be correlated with variations in introspective attitude, to give instructions about them would be to predetermine one of the variables. Later on, however, special instructions as to rate, and in a few cases as to pressure, were given in order to see if by purposely varying these objective factors a corresponding variation in attitude could be obtained, such as preceding experiments might have led one to expect would occur. When such special instructions were given they were always repeated in exactly the same words before each drawing. 
At the start the subjects were told to report in their introspections all conscious processes that accompanied the drawing of the figures. No hint was given as to what processes were the object of the investigation, and all attitudes reported were given equal consideration. Early in the investigation, however, it was found, as had been to some extent anticipated, that the only attitudes that appeared universally enough to admit of systematic study and correlation were attitudes designated as "certainty" and "uncertainty." It was therefore to these attitudes that the experimenter directed his attention, and the variations introduced into the experiment were aimed directly at bringing them more clearly into the light. Moreover, the questions by which the experimenter enlarged the subject's introspective report often had to do directly with the attitude of certainty, although they did not reveal to the subject the fact that this attitude was the object of the investigation. The subjects still continued to report all the other attitudes, images and sensations they had experienced. It may be that other observers would distinguish other attitudes within the certainty and uncertainty experienced in a drawing process. However this may be, our subjects reported definite conscious attitudes, some of which were designated as attitudes of certainty and others as the opposite attitudes of uncertainty, and the contrast between them holds whether or not they might be called by other names or each divided into a number of different sub-classes. Certainty, however, may be of two kinds, as reported by our subjects. These are designated as positive certainty and negative certainty. Positive certainty is the attitude that the drawing made is correct. Negative certainty is the attitude that the drawing made is incorrect in some definite way. Uncertainty is the attitude that the subject can't tell whether the drawing approximates the model or not. The distinction between positive and negative certainty involves a distinction between the attitude of certainty and the accuracy with which the subject feels the drawing to have been made. The attitude of certainty might be that the drawing was accurate or it might be that it was inaccurate. In either case the attitude was certainty.

Certainty in a drawing may give way to uncertainty and vice 
versa. Sometimes the attitude refers to one portion of the drawing, sometimes to the drawing as a whole. In the longer drawings there is reported a continuous attitude, which lasts throughout, varying between certainty and uncertainty. In shorter drawings the attitude may appear just as the subject finishes, and in such cases it usually refers to the drawing as a whole. There are, moreover, different grades to the attitude. At times certainty or uncertainty is more intense than at other times. These differences are reported by the subject in such terms as "good certainty," "only fair certainty," "a little uncertain," "typical uncertainty," "absolutely uncertain." etc.

In order to show a correlation between the attitudes reported and the objective records, it is evident that a fairly large number of experiments must be made, for the safety of this correlation depends upon the number of experiments and the taking of careful introspections. With the more complicated models that were used first in our experiments, twenty drawings were made of each model. With the simpler drawings, ten experiments were usually obtained for a series. In all about six hundred and fifty experiments were made.

We turn now to a consideration of the individual series of experiments.

\section{Series I. Practice Experiments}

The first experiments were conducted in the spring of I9I2, chiefly for the purpose of finding out whether the apparatus and method were adequate. As already stated, these preliminary experiments showed that a new method of recording pressure would have to be devised and substituted for the tambours.

The drawing process in this series was the same for all subjects, the model being a single straight, vertical line, $27 \mathrm{~mm}$. in length (Fig. 4, No. I). The task was to draw three vertical lines, equal in length to the model line, parallel to each other, and equal distances apart. They were to be drawn from top to bottom, and the whole process to progress from left to right. At the close of the drawing the subject gave his introspections, and named the order of certainty of the lines he had drawn. $\mathrm{He}$ 

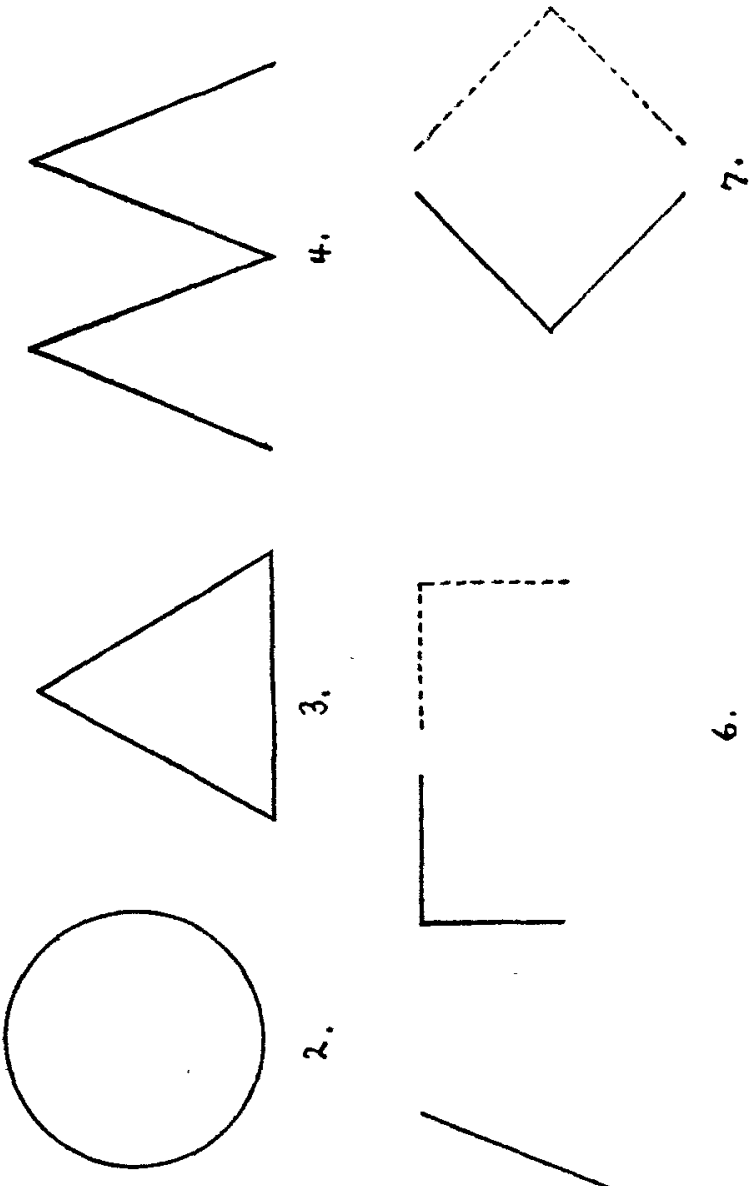

-
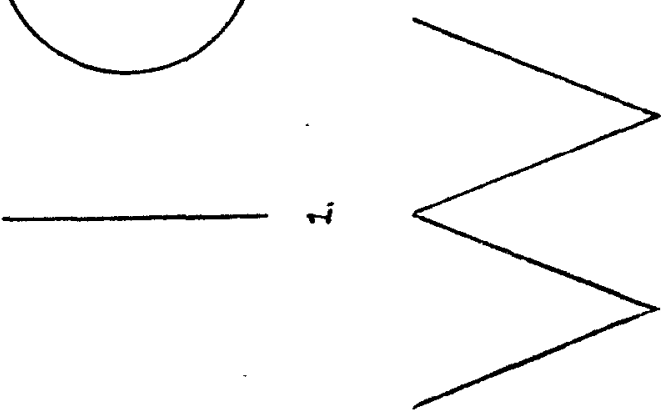

4 
ranked them from most certain to least certain. After a few experiments had been made, it was found that the first of the three drawn lines came to be regarded, without intention, as a sort of preliminary affair in which the subject simply "got the swing" of the process. The result was that he had little introspective knowledge of it, and it could not be compared with the other two lines. Since the introspective comparison of three lines was desired, this difficulty was obviated by having the subject draw four, the first of these to be a preliminary one to get the process started.

The lines in the drawing made by the subject were measured for accuracy as follows. First, their length was measured in millimeters. Second, an estimate of the straightness of each line was made. This was expressed in two ways. First the number of little waves or turns in direction was noted, and second the amount of deviation of the whole line from the vertical--determined with reference to a perpendicular to the horizontal boundary of the bottom of the space in which the subject drew. The distance from this perpendicular of the top of the line was measured and compared with a similar determination of the bottom of the line. Their difference, expressed in millimeters, gives the second measure of straightness. Third, the width of each interspace was calculated. This was done by taking the average distance apart of the two lines bounding it.

For purposes of time measurement the lines were divided into three equal parts and the time for each third calculated. In nearly every line, moreover, there were two periods, one at the beginning and another at the end, during which the pencil was touching the paper but not moving. The subject was not aware of the fact that he did not begin to draw the instant his pencil touched the paper, nor did he know that at the end of the line he held it still for a fraction of a second before raising it. The time for these two periods was also determined, making in all five time determinations for each line. Finally, the time between the end of each line and the beginning of the next, or the time in the interspaces, was also calculated.

These practice results are incomplete, the pressure records 
being defective, and are hardly significant except as they point toward later results. The records of the lines which each subject called most certain, and those for his least certain lines were grouped together and averaged. In the cases of $\mathrm{A}$. and $\mathrm{R}$. the average most certain line is drawn at a slightly faster rate than the average least certain line. In the case of $C$. the opposite is true here, but later results do not bear this out. With $F$. it was impossible to compare the most certain and least certain lines, because of lack of complete introspection.

Certain differences in imagery between the individual subjects came out in the practice series, and, as they keep appearing throughout the whole investigation, it will be well to describe them here.

A.'s imagery is almost entirely visual. In starting a drawing he has a visual scheme of it to be filled in. This risual scheme is followed throughout, and any marked deviation from it is pictured in visual terms. Sometimes the visual scheme is weak and the imagery vague. In making a drawing without a model it seems important for this subject to keep his eyes fixated upon the cardboard screen in the general direction of his hand. In drawing from a model he keeps his eyes upon the card, but his tendency is, as he expresses it, "to use the model as a suggestion rather than as a plan," that is, to draw rather from his own visual image of the figure than from the figure itself.

C. reports chiefly kinaesthetic imagery and sensations in the drawing process. Any plan or scheme he has at the beginning of a drawing is in kinaesthetic terms. He sometimes prepares for a drawing by making incipient movements with the pencil. $\mathrm{He}$ is easily disturbed by any slight awkwardness in the manner of holding the pencil, or in the position of the hand. In drawing from a model he follows it with his eyes throughout. In drawing without a model he does not keep his eyes fixated in a particular way, but gets his hand placed carefully and then looks away. He reports visual imagery too, but his visual image always comes up after the drawing has been made, as the last stage of the process.

F. reports imagery of both types. The most prominent kind 
of imagery with him is visual-motor. He images the developing figure as he draws, and he often risualizes the moving pencilpoint as well.

R. reports less imagery than any of the other subjects. What he does report is chiefly visual, with occasional kinaesthetic, imagery. Often incomplete risual inages appear. Part of a line will be visualized and the rest will not appear. Sometimes a line will be visualized as heavy and dark at one end, but gradually shading off into nothing at all at the other end.

\section{Series II. II a and IIb}

The remainder of the experiments were made in the fall of 1912 , and the winter and spring of 1912-13. In the present series each subject was given a different figure to draw, and so a different task. Series IIa is in each case a variation upon Series II. In treating these series we will take up the different subjects separately.

Subject A.-A. was given as a model a circle, $27 \mathrm{~mm}$. in diameter (Fig. 4, No. 2). He was instructed simply to copy the circle exactly, beginning at the top and drawing in the anticlockwise direction, using a finger movement and not shifting the position of his hand during the drawing. The anti-clockwise direction was chosen because it seemed to the subject that it would be more natural for him than the clockwise direction. After taking a series of twenty such anti-clockwise drawings a variation was introduced by having the subject draw the circle in the opposite direction, still beginning at the top. A series of twenty such clockwise drawings was also obtained, forming Series IIa. Then, after a long interval (October to April), during which a large number of other experiments had intervened, another series of ten anti-clockwise drawings was made. These form Series IIb.

The method of measurement for these drawings was as follows. For accuracy, the approximate center of the circle drawn by the subject was found with a compass. Then four axes were drawn through it, the vertical, the horizontal, and the two diagonal axes. When compared with the diameter of the original 
circle, the lengths of these axes give a good estimate of the accuracy of the circle as to size. When compared with each other they give a good measure of the roundness of the circle. In measuring the accuracy of the circle, also, the distance from end to end, that is, the amount by which the end point failed to meet the starting-point, was measured in millimeters. This measurement is expressed as the "distance from end to end" under the abbreviation "E. to E."

For measuring time changes during the process of drawing, the circumference was divided into quarters. A more minute division of the circumference seemed unnecessary because of the character of the subject's introspections. These were nearly always given in terms of halves or quarters of the circle, the subject making these divisions guiding marks in his description of the course of mental processes during the drawing. It was therefore evident that any changes in drawing rate which could be correlated with a change of attitude should show in a comparison of the quarters. The end-points of the vertical and horizontal axes were taken as marking the boundaries of the quarters of the circumference. This, of course, is not absolutely accurate, as the drawn circle was never perfectly round, but it is exact enough for our purpose. The pressure record was also divided into four quarters.

For brevity and convenience in exposition, the results of these series will be treated as a whole by a consideration of the averaged measurements of the twenty drawings and a summary of the introspection. The individual drawings show such uniformity in their characteristics that this may be done.

The introspections for both Series II and IIa show that a continuous attitude accompanied the drawing of the circle from start to finish. The anti-clockwise circles are more certain than the clockwise. This is shown both in the relative number of attitudes of certainty reported, and in the general remarks of the subject. In both types (clockwise and anti-clockwise) the drawing of the second half is accompanied by less certainty than the first. In Series II, the anti-clockwise circle, a point of maximum uncertainty is sometimes located, and when it is thus mentioned, 
as it is in six of the experiments, it is always located as either in the third quarter of the circle or between the third and fourth quarters, at the place where the figure III appears on a clock-face. In Series IIa (clockwise) a point of maximum uncertainty is sometimes mentioned; but it does not show any uniformity in the place at which it occurs, except that it is usually somewhere in the second half of the drawing.

The accuracy and time measurements for Series II and IIa are compared in Table $\mathrm{I}$.

TABLE I

Subject A

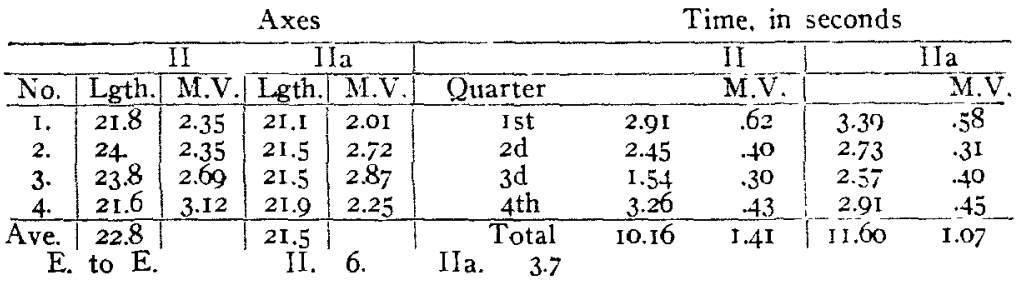

It will be seen from this table that the circles are very nearly the same size. Their average diameters differ by only $1.3 \mathrm{~mm}$. They differ, however, in shape, the anti-clockwise circle being slightly elongated along its first diagonal axis. The clockwise circle shows less difference in the lengths of its axes, and is more nearly round. The distance from end to end is less too. Thus, the anti-clockwise circle is a little more accurate than the other in size, while the clockwise one is slightly more accurate in shape. So the less certain circle is a little less accurate than the other in size, but more accurate in shape.

We turn now to the consideration of the time records. It will be seen from the table that the four quarters of the circle vary a great deal from each other in the speed with which they are drawn. In the anti-clockwise circle the drawing begins slowly in the first quarter, becomes somewhat faster in the second, is fastest in the third, and then in the fourth is slower than ever before. Thus the maximum change of speed comes between the third and fourth quarters, and the change is a retardation. In the other circle we find smaller differences between the times 
of the respective quarters. The third quarter is again the fastest, but the difference between it and the fourth is not as great. Instead, the greatest difference is between the first and second quarters, but this too is smaller than that between the third and fourth quarters of the other circle. There the difference was I.72 sec., here it is only .66 sec. Moreover, the change in the first case is a decrease, here it is an increase in speed. In connection with these characteristics of the time records it will be remembered that in the anti-clockwise circle the point of maximum uncertainty, when it was located, came in the third quarter or between the third and fourth. Also, that while less certain as a whole than the anti-clockwise circle, the clockwise one does not show any definite point of maximum uncertainty. Thus, in so far as we have been able to locate a point of maximum uncertainty, that point comes at the place where the greatest change in speed is taking place, and that change is a decrease. In general the clockwise circle is less certain than the anti-clockwise one, and the table shows that it is drawn more slowly. The second half of each type of circle is less certain than the first, and the table shows that in each case the first half is drawn at an increasing, the second half at a decreasing rate. The point of maximum uncertainty comes in the anti-clockwise circles at the point where the figure III is located on a clock-face. This is the same point with reference to the hand as the end of the first quarter in the clockwise circle. In the first case uncertainty is reported, in the second certainty. In the first case there is a greater change in rate and it is a decrease, whereas in the second case the change is smaller and it is an increase.

The pressure records show certain similar characteristics that hold throughout. In the records for both circles there is a gradual increase of pressure at the beginning, which lasts as a rule throughout the first half, and sometimes as far as the middle of the third quarter. When the third quarter is reached there is usually a decrease in the pressure curve of the anti-clockwise circle. This decrease appears in fourteen of the twenty drawings of Series II. In two drawings it does not appear, and in the remaining four the records are defective. This decrease in pres- 
sure comes at the same part of the circle as the great decrease in rate revealed by the time records. It is also at the place at which the maximum uncertainty is reported when it is reported at all. In the two cases where there is no decrease in the third quarter the introspections show that the circles are unusually certain ones. Thus, the decrease in rate and pressure between the third and fourth quarters seems connected with the appearance of uncertainty. In Fig. 5. No. I, we have a tracing of a curve of this sort from Series II. This curve is reduced in its length but not in its height. The differences in the height of the original curve are so slight compared with its great length that they would not show well if the reduction were made proportional throughout. All the tracings in this article, however, except those in Fig. 5 and two in Fig. 6, are made proportional throughout. Reducing is done by means of a pantagraph. In all the curves a rise indicates an increase in pressure.

The pressure curves of Series IIa, the clockwise circles, show much the same characteristics as the others in their first halves. There are, however, a somewhat larger number of changes in pressure. The second half, in six cases out of the twenty, shows a decrease between the third and fourth quarters. In three of these cases it is accompanied by an attitude of uncertainty. In Fig. 5, No. 2, is given a typical pressure curve for a clockwise drawing. It shows in its first half the same general characteristics as the curve for the other circle, but it has not the decrease between the third and fourth quarters. In Fig. 5, No. 3, we have one of the clock-wise circles which differed from the others of the series markedly. The subject said in his introspections on this circle that he started not with the intention of following the model around as he drew, but rather to draw the circle in one quick sweep. The time records show that this circle was drawn nearly twice as fast as the average, and there is less slowing up in the second half. The result was that the changes in attitude were reduced in degree. The difference in certainty between the first and second halves was less markd. The curve shows scarcely any difference from beginning to end. So we find that in this experiment where the typical difference in certainty is reduced, 

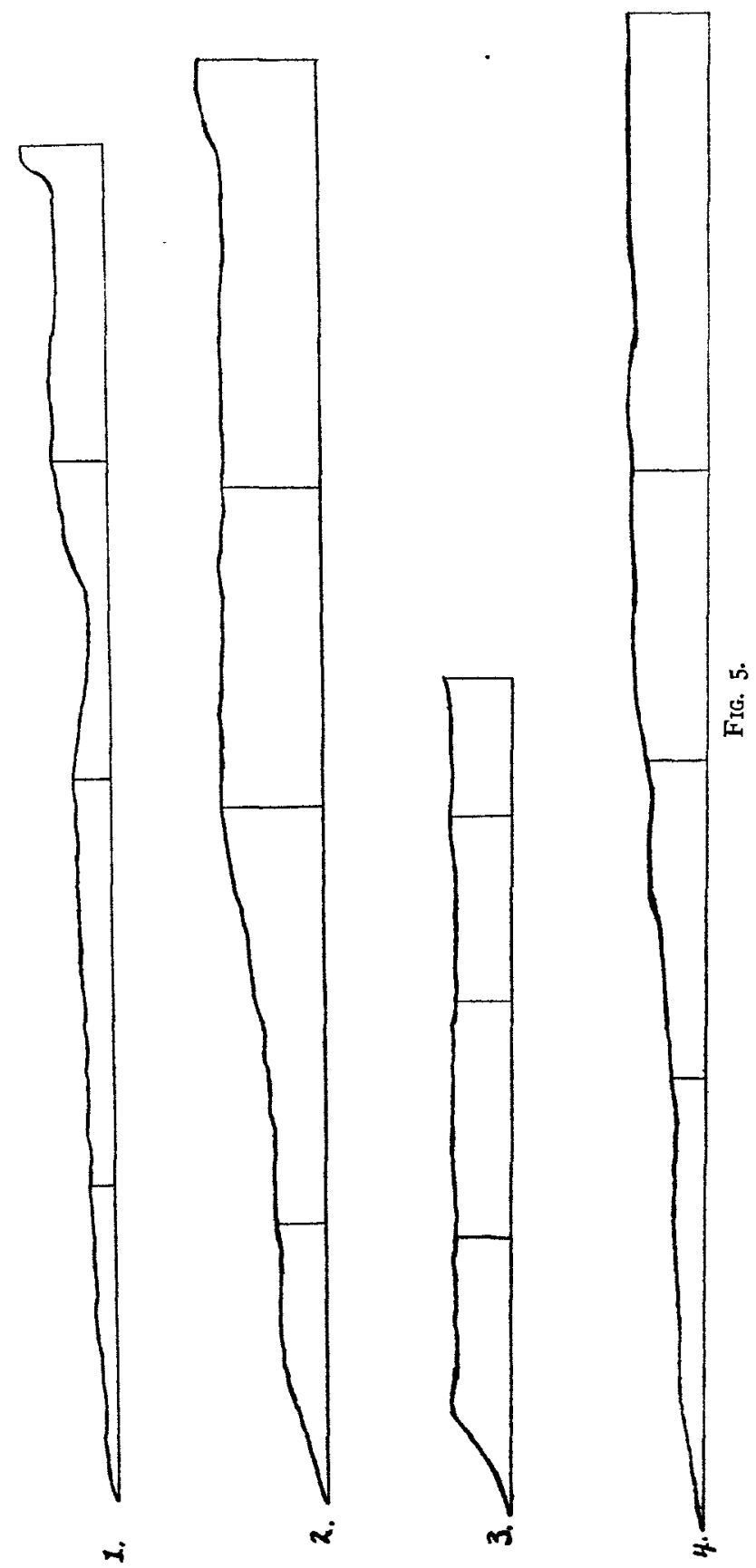
the difference in the character of the pressure curve for the two halves is also reduced.

Summing up the results for Series II and IIa, we find that :-

(I) The anti-clockwise circle, which the subject said at the start would be more natural for him, is found in general to be drawn with more certainty than the other one. The first half of each circle is more certain than the second half.

(2) The anti-clockwise circle is more accurate in size, but less accurate in form than the clockwise one.

(3) The clockwise circle is drawn at a slower rate than the anti-clockwise one. In each circle the first half is drawn at an increasing rate and the second half at a decreasing rate.

(4) The pressure curves for the two circles are similar in that there is a gradual rise throughout the first half. The second halves of both curves differ from the first halves. In the anticlockwise drawings there is a decrease of pressure between the third and fourth quarters. In the clockwise ones this decrease sometimes appears, but there is no regularity about it.

(5) Attitudes of uncertainty go with the second halves of the circles, and especially with the middle of the second half of the anti-clockwise one. At these points there is a decrease in the rate of drawing, and, in the anti-clockwise circle, a decrease in pressure.

At the end of all the experiments a series of ten anti-clockwise circles was made, Series IIb. The results of this series appear in Table II, which follows the plan of Table I.

\begin{tabular}{|c|c|c|c|c|c|}
\hline \multicolumn{3}{|c|}{ Axes } & \multicolumn{3}{|c|}{ Time } \\
\hline No. & Lgth. & M.V & Quarter & & MI.V \\
\hline t. & I4.7 & I. 2 & Ist & 3.88 & .51 \\
\hline 2. & I5.I & I.I & 2nd & 2.89 & .45 \\
\hline 3. & $x_{4.5}$ & 1.2 & 3 rd & 2.12 & .26 \\
\hline 4. & 14.4 & I. 2 & $4^{\text {th }}$ & 3.30 & .38 \\
\hline Ave. & I. 6 & & Total & 12.19 & 1.12 \\
\hline
\end{tabular}

This table shows that the circle is now drawn more accurately as far as its shape is concerned, but it is made much too small. The subject gave no indication in the introspections that he was aware of the small size of his drawing. This variation was intro- 
duced primarily to see if there would be any indication of practice effect in the results, and what the effect of this would be upon the attitudes reported. The subject noted some indication of practice effect. This did not appear immediately, but was reported first in the fifth drawing of the series.

In general the drawings of this series are more certain than those of Series II. The subject is able to tell more clearly just what he has done, he reports more attitudes of both positive and negative certainty, and fewer attitudes of uncertainty. There is no longer a specific place at which the maximum uncertainty appears. It is noted only once, and there it is in the fourth quarter. An examination of the time records shows that the drawings as a whole are now made more slowly than in the other series, and there is less difference in time between the third and fourth quarters.

The pressure records of this series are not very satisfactory, owing to the very slight pressure with which the subject drew. Four of the ten are not good enough to give results. In the other six the pressure is fairly constant in its increase from beginning to end, or else it increases quickly at the beginning and maintains about the same level to the end. There is never a decrease between the beginning and the end. One particularly certain drawing was obtained-one in which no uncertainty is reported anywhere in the course of it. The pressure curve for this drawing is illustrated in Fig. 5, No. 4. It will be observed that it rises gradually throughout, with no marked changes, and never a decrease.

In this series, therefore, we find that with the greater certainty revealed in the introspections there is a change in the time and pressure characteristics, this change being in the direction which we have already found to tend toward certainty. The circle as a whole, however, is drawn more slowly than before. Previous results have seemed to indicate that certainty goes with a fast rate of drawing. Thus it would seem that in a long drawing of this character the rate of the total drawing is less important for the attitude than relative rates of the different parts.

Subject C.-With C., the model in Series II and IIa consisted of an equilateral triangle, the sides of which were $28 \mathrm{~mm}$. in 
length. This is No. 3 in Fig. 4 . In Series II the subject was instructed to draw the triangle beginning at the apex, then drawing obliquely downward to the left, then horizontally to the right, and then obliquely upward to the left to the apex again. Twenty drawings were made in this way. In Series IIa the subject began to draw the triangle at the lower left-hand corner, going first along the horizontal line to the right. then oblicuely upward to the apex, and obliquely downward to the startingpoint again.

This figure proved to be the least satisfactory of all those used. The drawing of it is not really a continuous process like the drawing of the circle, because the subject pauses at the corners. On the other hand, the three lines are not repetitions of the same mechanical process. as are the three vertical lines of the practice series. That these characteristics are unfavorable to the appearance of contrasts in attitude which can be reported, is shown by the character of the introspections. There was no continuous, changing attitude as in the case of the circle. On the other hand, the lines of the triangle were not compared with each other as were the lines of the practice series. Thus, different parts of the same figure cannot be compared, and the only comparison the introspections allow is of one whole figure with another, or a certain part of a whole figure with a similar part of another.

The method of measurement was to measure the lines and angles of the drawn triangle and the amount by which the end failed to meet the beginning. The lines are numbered I, 2, and 3 in the order drawn in each case. The angles are similarly numbered.

Table III gives the accuracy and time records for Series II and IIa. The average of twenty drawings is given in each case. The length of the lines is given in millimeters, as is also the distance $\mathrm{E}$. to $\mathrm{E}$. The angles are given in degrees.

Table III Subject C.

\begin{tabular}{|c|c|c|c|c|c|c|}
\hline \multicolumn{7}{|c|}{ II } \\
\hline No. & Lgth. & M.V. & Angles. & M.V. & Time & M.V. \\
\hline I. & 25.4 & 3.7 & 55.8 & 1.8 & 2.30 & .57 \\
\hline 2. & 36.4 & 5.9 & 70.9 & 3.9 & 2.67 & .63 \\
\hline 3. & 30.4 & $3 \cdot 3$ & 57.2 & 2.6 & 2.14 & $.9 \mathrm{I}$ \\
\hline \multicolumn{4}{|c|}{ E. to E. 16.5} & To & 7.11 & 1.39 \\
\hline
\end{tabular}




\begin{tabular}{|c|c|c|c|c|c|c|}
\hline \multicolumn{7}{|c|}{$\mathrm{IIa}$} \\
\hline No. & Lgth. & M.V. & Angles. & M.V. & Time & M.V \\
\hline I. & 43.8 & 5.1 & 79.9 & 3.8 & 5.40 & 1.46 \\
\hline 2. & 34.7 & 5.9 & 47. & 4.7 & 4.73 & 1.69 \\
\hline 3. & 40.3 & $3 \cdot 3$ & 50.3 & 4.5 & 4.90 & 1.57 \\
\hline
\end{tabular}

The large mean variations shown in this table indicate that there was very little uniformity in the drawing in either series, especially in the time. This makes it impossible to draw any conclusions, and owing to the difficulty of getting definite introspective comparisons between well-defined parts of these drawings, it is not possible to derive much of value from the pressure records. The only possible correlation between certainty and pressure in Series II is a very broad one. Of the fourteen cases in which drawings had been designated as certain as a whole or uncertain as a whole, five were called certain and nine uncertain. As a whole the pressure curves of the certain drawings are more smooth and even than those of the uncertain drawings. The changes in pressure are more gradual and less frequent in the certain drawings than in the others. The difference between the certain and uncertain curves is not very great to be sure, but it holds in all but two cases out of the fourteen. Fig. 6 gives in No. I a tracing of a typical curve for a certain drawing, and in No. 2 one for an uncertain drawing. These curves, as in the case of the circles, are so long that a reduction of their height in proportion to the reduction of their length would make the changes in height very small. They are therefore reduced more in length than in height.

In Series IIa no such comparison of whole drawings is possible as the subject there gives detailed introspections of the process, but does not give an indication of an attitude toward the figure as a whole. There is, however, one very marked peculiarity which appears in some of the pressure curves. This is a sort of "plateau" at the end. It will be remembered that in this figure the end comes at the lower left-hand corner, and the last line is the downward diagonal from upper right to lower left. At the end of this line and completing the figure, this plateau occurs in eight out of the twenty cases, being absent in the other twelve. 

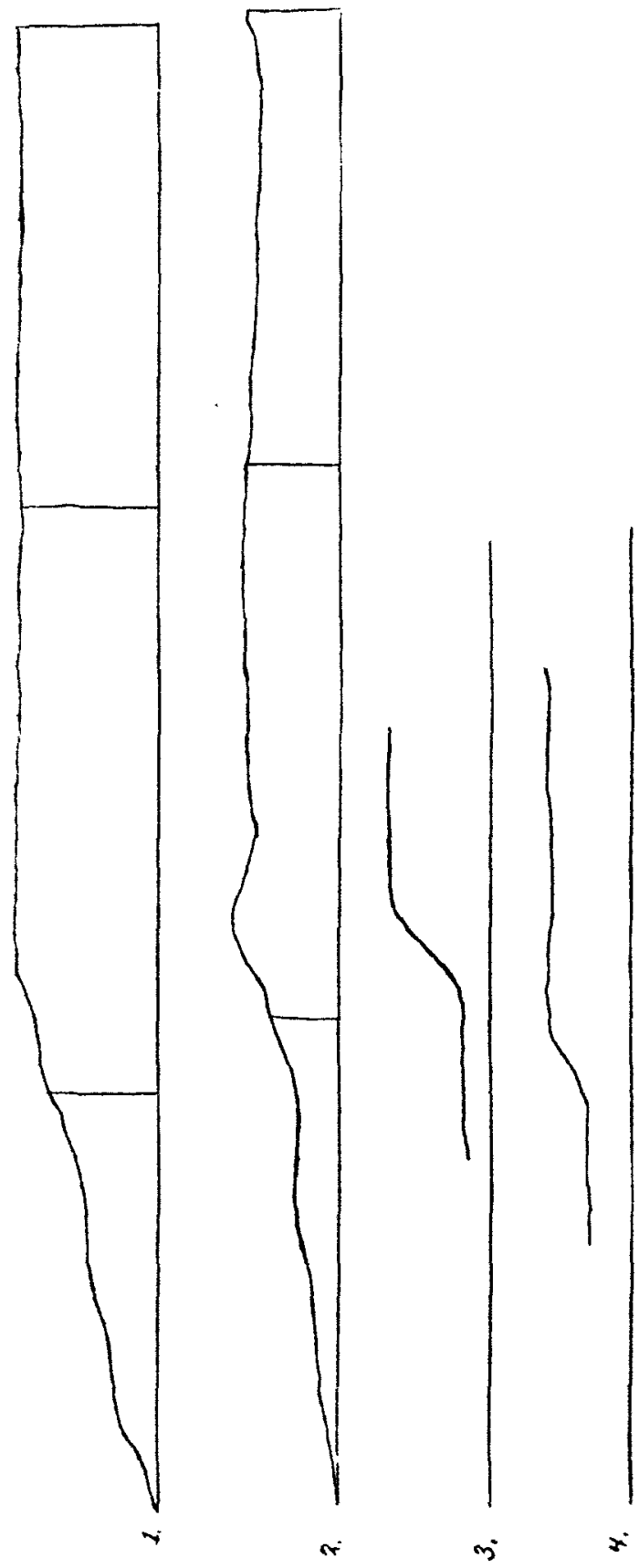

ن 
In Fig. 6, No. 3, a marked plateau is illustrated. No. 4 is an ending of the same sort, but not as marked, and No. 5 illustrates the end of a curve in which there is no plateau. The reduction of these is uniform throughout. The introspections show that in each drawing where a plateau appears at the end of the pressure curve there was an attitude of certainty at the instant of ending. This attitude appears in all but two of the eight cases where the curve shows a plateau, and it appears in only three of the other twelve drawings of the series. This attitude often gives way immediately to a reflective attitude of uncertainty toward the process as a whole, and this attitude of uncertainty seems closely bound up with the visual image which comes up just after the completion of the drawing.

Subject F.-The model used with F. in Series II consisted of four slant lines, $27 \mathrm{~mm}$. in length, put together somewhat in the form of an M. For Series IIa the model was the same figure inverted. The first figure is illustrated in Fig. 4. No. 4, and the second one in Fig. 4, No. 5. In both these figures the subject was instructed to draw the lines all from top to bottom, this being the way that seemed most natural for him. There are certain similarities and certain differences in the process of drawing these two types of figures. Lines $I$ and 3 of the first type correspond to lines 2 and 4 of the second in that they are drawn from upper right to lower left, and are parallel to each other. Similarly, lines 2 and 4 of the first figure correspond to lines I and 3 of the second in that they are drawn in the other oblique direction and form a parallel pair. The lines of both figures are the same in that they are drawn from top to bottom in each case and are slanted at the same angle from the perpendicular. An important difference between the two figures is that in the first the subject is drawing down from points, while in the other he is drawing down to points. There is a difference in the mechanical difficulty of drawing a line from upper right to lower left and in the other oblique direction. The former direction the subject pronounced the easier, mentioning it several times in the course of the series.

The method of measurement was as follows. First, the length 
of each line was meastured in millimeters. Then the straightness of the line was indicated by a figure expressing the number of slight deriations that occurred in it. The direction of the line was determined and expressed in terms of the number of millimeters by which the line deviated from the correct slant. Finally, the amount by which the successive lines failed to meet each other at the points was also determined in millimeters.

For time measurement the four lines were divided into halves. The time was determined in each line. first for the period at the start during which the pencil was down but not moving, then for each of the two halyes, and then for the period at the end during which the pencil was at rest. The time elapsing between the end of one line and the beginning of the next. or the time in the points, was also determined.

Table IV gives the accuracy averages for the twenty drawings

TABLE IV

Subject $F$

\begin{tabular}{|c|c|c|c|c|}
\hline \multicolumn{5}{|c|}{ II } \\
\hline No. & Lgth. & Str. & I) ir & Points \\
\hline I. & 309 & I.I & I 6 & 5.72 \\
\hline 2. & 23.9 & I.7 & 1.3 & 4.75 \\
\hline 3. & 265 & 12 & 3.2 & 3.25 \\
\hline 4. & 21.7 & 2.1 & 13 & \\
\hline \multicolumn{5}{|c|}{ Ila } \\
\hline No. & Lgth & Str. & Dir & Points \\
\hline I. & 29.0 & 2.0 & 4.3 & 4.05 \\
\hline 2. & 25.3 & I. 6 & 2.3 & 3.22 \\
\hline 3. & 22.6 & 1.5 & 2.5 & 4.45 \\
\hline 4. & 28.1 & 1.9 & 2.3 & \\
\hline
\end{tabular}

of each series. It will be seen from this table that in Series II, lines $\mathrm{I}$ and 3 are more accurate, except in direction, than 2 and 4 , while in Series IIa just the opposite is the case. So, the lines which are mechanically easiest to draw are those which are drawn most accurately. There is a certain correspondence between parallel pairs in the same figure, and in each series line I is drawn longer than any of the others.

The time records for Series II and Ila are given in Table Vin each case the average of twenty experiments. The smaller time deterninations-those for the parts of the lines-do not 
show any marked uniformities and are omitted from this table. Under "Time" is given the average time for each line. Under "Rate" is given the average rate at which it is drawn. The rate is determined by dividing the length of each line by the time it took to draw it. This gives the rate in millimeters per second, and the average of these determinations appears in the table. Under "T. P." is given the average time between the ending of one line and the beginning of the next.

Of the columns in this table those for rate are the most important. In II the rate for line I is higher-a greater number of millimeters per second-than that of any of the other lines. As a pair too, $I$ and 3 are more rapidly drawn than 2 and 4 , just

TABLE V

Subject F.

\begin{tabular}{c|c|c|c|c|c}
\hline & \multicolumn{2}{|c|}{ II } \\
\hline No. & Time & M.V. & Rate & M.V. & T.P. \\
\hline I. & 4.27 & .38 & 7.40 & .96 & .92 \\
2. & 4.32 & .37 & 5.67 & .87 & 1.08 \\
3. & 4.10 & .46 & 6.47 & 1.03 & .82 \\
4 & 4.44 & .43 & 4.85 & .57 & \\
\hline
\end{tabular}

\begin{tabular}{c|c|c|c|c|c}
\hline \multicolumn{7}{|c|}{ IIa } \\
\hline No. & Time & M.V. & Rate & M.V. & T.P. \\
\hline I. & 4.36 & .33 & 6.69 & .65 & .84 \\
2. & 3.69 & .36 & 7.05 & .77 & .86 \\
3. & 3.86 & .33 & 5.92 & .56 & .89 \\
\hline 4 & 3.68 & .31 & 7.67 & .92 & \\
\hline
\end{tabular}

as in the accuracy table they are found to be drawn longer. In Series IIa we find that 2 and 4 are more rapidly drawn than $I$ and 3 , though $I$ is drawn fairly fast. The accuracy table shows that these fast-drawn lines are long, so that in general the tendency to draw at a fast rate and the tendency to make the line long go together.

From the introspections it is possible to get in a general way the order of certainty of the four lines in Series II and Series IIa. There is sometimes enough difference between the four lines introspectively to enable the subject to name them in their order of certainty. Where this is not given it is often possible to tell from the general character of the introspective report what this order 
was. The order of certainty most frequently given in Series II was $1,3,2,4$. This order was given five times. The order of certainty is given in all only nine times, and no other order of certainty appears more than once. This order receives support also from the introspections in which the certainty of one or two lines is spoken of, but the complete order not given. Line $I$ is called most certain in every case, line 4 is called less certain than line 2 in all but two cases. The general outcome of the introspections of Series II, as far as the order of certainty is concerned, is that line $I$ is the most certain line, that $I$ and 3 are more certain than 2 and 4 , and that the most usual order of certainty is $1,3,2,4$.

Recurring for a moment to the accuracy and time records, we find that the most certain line $I$ is the longest and most rapidly drawn. Line 3 is next in length and rapidity, and then follow lines 2 and 4 respectively.

The introspections of Series IIa are somewhat more definite than those of Series II. Line $I$ is again most certain in all lut two of the twelve cases in which the order of certainty is given. Lines 2 and 4 are much more certain in this series than in the other one, and line 3 is called least certain every time it is compared with the others. The typical order of certainty for this series is $1,4,2,3$.

Turning to the records of accuracy and time for this series, we find that the certainty of line $I$ and of lines 2 and 4 goes with greater length of line and faster rate of drawing. The greater length and faster rate of line $I$ is, however, not as marked here as in the other figure where it is drawn in the other easier oblique direction. Lines 2 and 4, which are more certain in this figure than in the other one, are also drawn at a faster rate here than they were there. Line 3 , which is least certain in this series, is drawn most slowly and is shortest. So it tends to hold here too that certainty goes with a long line rapidly drawn.

One other point must be considered before we go on to the pressure records. It was emphasized above that lines drawn from upper right to lower left were mechanically easier for the subject to execute than the lines drawn in the other oblique 
direction. Does certainty simply go with this mechanical ease of drawing? In Series II it evidently does. Lines $I$ and 3 are more certain than the mechanically harder lines 2 and 4 . If it is true of the other series as well, lines 2 and 4 should be more certain than lines $\mathrm{I}$ and 3 . We find that they are more certain than 3, but not as certain as $r$. If we should try to show a correlation between certainty and the mechanical ease of drawing, we would be unable to explain how line I, mechanically easy in one case and mechanically difficult in another, is yet most certain in each case. The fact that it is the first line drawn in each case doubtless has something to do with it. but this will not help our explanation unless the fact that it is the first line drawn makes the process of drawing it characteristic in some way that will show in our records. In the cases of the other lines we have found a correlation of certainty with length of line and fast rate. This does not hold in the case of line $I$ in Series IIa in comparison with lines 2 and 4 of its own series, for although it is longer and drawn at a faster rate than the other three lines which are drawn in the same direction (II, 2 and 4 . IIa, 3 ) it is not drawn faster than, nor is it much longer than, lines 2 and 4 of its own series. Its certainty must therefore be connected with some other factor which we have not yet observed.

We find such a factor the moment we examine the pressure curves. The pressure curves for line I conform to the same type throughout both series, except two cases in Series IIa where alone line $I$ is called uncertain. The form of the curve is a gradual steady rise to a maximum which is held without decrease to the end. Fig. 7 shows two curves (Nos. I and 2) for line I, the first from Series II, the second from Series IIa. No. 3 is a curve from one of the two drawings in Series IIa in which line I was called uncertain. Its variation in form is marked. We find here, therefore, in line $\mathrm{I}$, that certainty and a definite type of curve go together, and that this holds regardless of the mechanical ease or difficulty with which the line is drawn.

In the later lines of the drawings the curves show greater pressure than in line I, and a somewhat different shape. They rise more quickly and their increase is not quite as uniform. Fig. 7 , 


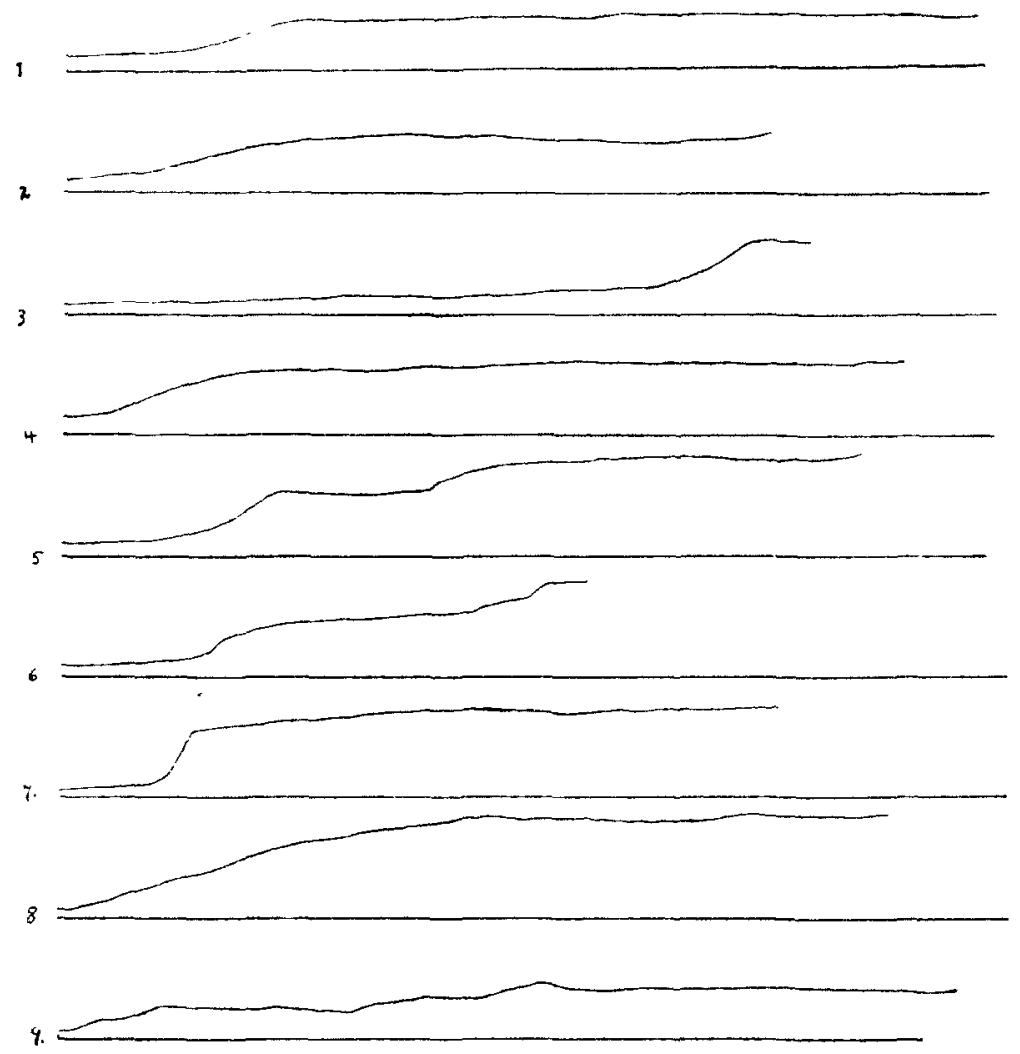

FIG. 7.

No. 4, shows a pressure curve from line 2 in the first figure (Series II) in which 2 was called next to I the most certain line in the drawing. Below it is given in No. 5 an example in which this line was called least certain of the four. Fig. 7 , Nos. 6 and 7 , show examples of line 3 in Series IIa. In 6 the line was certain, in 7 uncertain. In 8 and 9 of Fig. 7 there are illustrated two pressure curves of line 4 in the first figure (Series II). In No. 8 line 4 was certain, in No. 9 it was uncertain.

This correlation between certainty and a definite type of curve, and uncertainty and a variation from that type holds in every case for line I in both figures. It also holds where a line, usually certain, is pronounced particularly uncertain. But it does not 
hold between small differences in certainty. There are examples in the records of both figures where there is no appreciable difference between the curves of lines 2 and 3, and yet one is called more certain than the other. Evidently, then, only wide contrasts in subjective certainty show corresponding differences in the pressure records under the conditions of this experiment.

Summarizing the results of this experiment with subject $F$. we find that:-

( 1 ) In general certainty goes with a longer line and a faster rate of drawing than does uncertainty.

(2) The lines which are mechanically easy for the subject to execute are usually the lines drawn in this way.

(3) Line $I$ is most certain in each figure, though in the first it is mechanically easy and in the second mechanically difficult. This certainty is correlated with a definite form of pressure curve which is followed in the drawing of line I in both figures, and is departed from only in the two cases in which line $I$ is called uncertain.

(4) In the other lines marked contrasts in subjective certainty are reflected in the pressure curves.

Subject $R$.-In Series II the experiment with R. was identical with that of the practice series after the preliminary line had been added to the other three. It consisted in drawing the four parallel vertical lines from top to bottom. In Series IIa a variation was introduced. This was simply that instead of being drawn from top to bottom the lines were drawn from bottom to top.

One change was made in the method of measurement. Instead of dividing the lines into thirds and finding the time for each third, the lines were divided into halves. Twenty drawings were made in each series, and the usual full introspections were taken. The subject was able in almost every case to name the lines in their order of certainty. No uniform order of certainty developed. The succession of drawing, or the position of a line in a drawing had no effect upon its certainty or uncertainty.

A comparison of the accuracy and time averages of Series II and Series IIa shows that the lines when drawn from bottom to 
top (IIa) are longer, less straight (though as good in general direction), and more slowly drawn, than the lines of the other series where they are drawn from top to bottom. These differences cannot be correlated with a general difference in certainty between the two sets of lines. The introspections reveal no general difference which would enable us to say that one series had been more or less certain than the other. Yet, since the two series show such marked differences in the accuracy and time records, we must keep the two series separate when we compare the records of the most certain lines with those of the least certain ones, as we now proceed to do.

The averages of the most certain lines and least certain lines are given in Table VI. The smaller time determinations are omitted as they show no differences between the most certain and least certain lines not expressed in the time for the whole line. The average rate, however, is included in the table.

TABLE VI

Subject R.

\begin{tabular}{|c|c|c|c|c|c|c|c|}
\hline II & Lgth & M.V & Straighiness & Time & MI & Rate & $M . V$ \\
\hline Most & 25.4 & 3.1 & (.9) I & 1.07 & .22 & $2+.2$ & 4.5 \\
\hline $\begin{array}{l}\text { Least } \\
\text { Ila }\end{array}$ & 24.6 & 2.8 & (.94) I.I & I.IO & .22 & 230 & 3.2 \\
\hline $\begin{array}{l}\text { Most } \\
\text { Least }\end{array}$ & $\begin{array}{l}31.9 \\
32.6\end{array}$ & $\begin{array}{l}2.2 \\
1.8\end{array}$ & 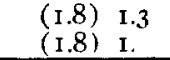 & $\begin{array}{l}1 .+6 \\
1.57\end{array}$ & $\begin{array}{l}.21 \\
.24\end{array}$ & $\begin{array}{l}22.2 \\
21.7\end{array}$ & $\begin{array}{l}2.2 \\
3 .\end{array}$ \\
\hline
\end{tabular}

In accuracy the most and least certain lines are just about the same. In the time values, however, there is a difference, the most certain lines being drawn at a slightly faster rate than the least certain whether the lines are made from top to bottom or from bottom to top.

As has been said, the subject gave the order of certainty of the lines in every case. This order of certainty was, therefore, compared in every case with the characteristics of the pressure curves. It soon appeared that the line which came first in the order of certainty always had a definite form of pressure curve, and that the other lines differed from this type in a greater or less degree according to their degree of certainty. So marked was this form of curve and so universally did it hold, that it was possible to tell solely from an examination of the pressure curves 


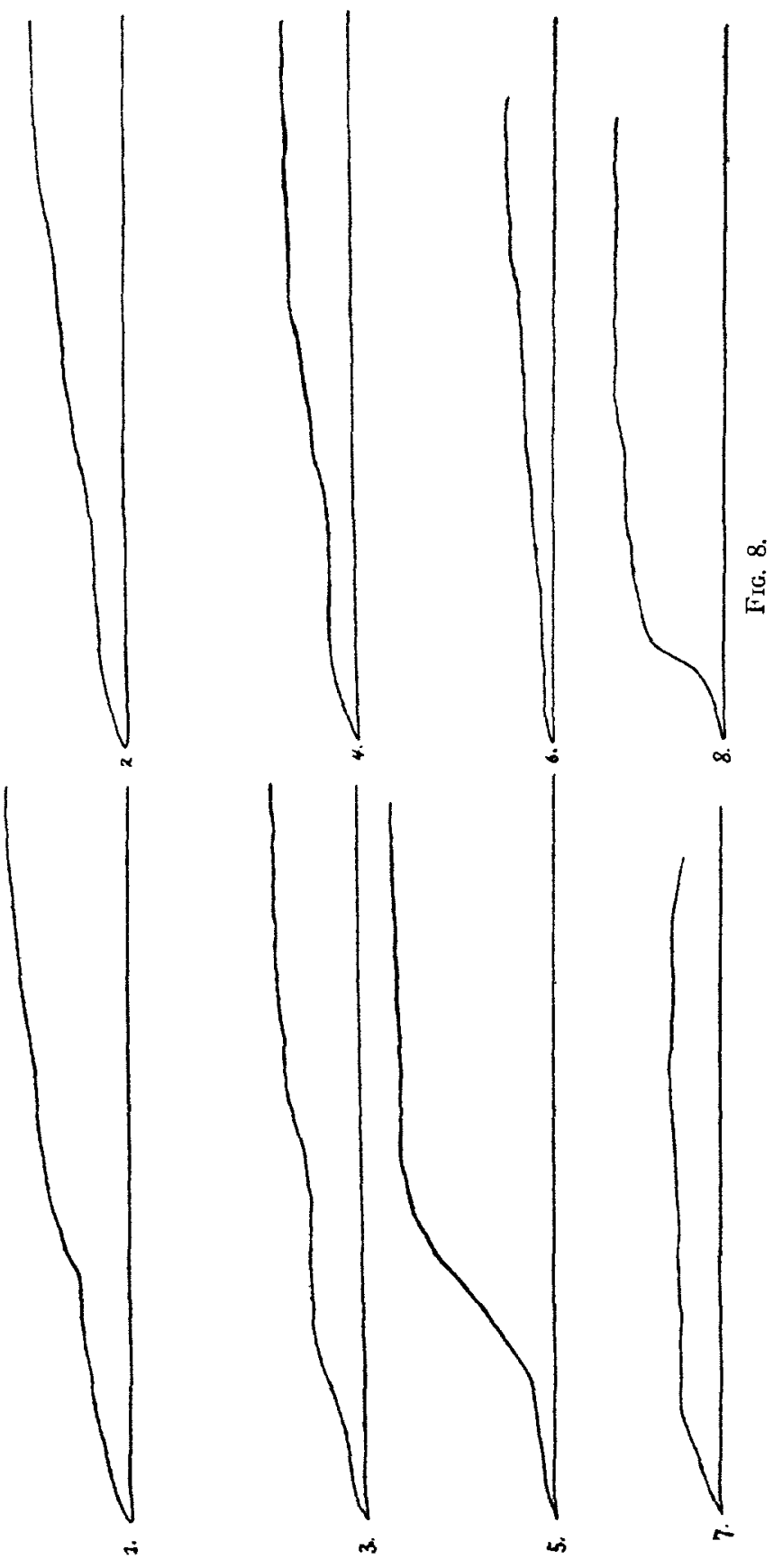


which line had been called most certain, and in nearly every case the order in which the other two followed it. This was true both of Series II and Series IIa. The "certainty" form of curve is the same for the drawings of each series. Fig. 8 shows some examples of curves taken from both series. Nos. I and 2 are certainty curves from Series II, Nos. 3 and 4 certainty curves from Series IIa. It will be observed that the curves follow the same form whether the lines are drawn from top to bottom or from bottom to top, reversing the mechanical process of drawing. The remaining curves in Fig. 8 are tracings of uncertainty curves from both series. They vary from the certainty type in two ways. Either the increase at the start is too rapid, as in No. 5 , or the increase is more gradual as in No. 6. No. 7 is a curve from a line which the subject called "uncertain at the end." This curve shows a decrease of pressure at the end.

Not only does the curve for certainty follow a definite form, but it shows a regularity in its height as well. In the great majority $(80 \%)$ of the cases the pressure curve for the most certain line is between the curves for the other two lines in height. So there is a general tendency for the certain line to be that one which is drawn with a medium pressure.

This experiment, therefore, has shown certainty in a certain part of the drawing process going with a fast rate of drawing in that part and with a definite form of reaction as shown by the pressure curve. The accuracy results which show no difference in accuracy between the certain and uncertain drawings are interesting as showing that an accurate drawing does not necessarily represent the kind of reaction characterized by certainty. The accurate drawings vary as to certainty or uncertainty with the character of their pressure curves. The same is true of the inaccurate ones.

\section{Series III}

In this series no model was used and the subjects were all given the same task. They were instructed to make a dot, raise the pencil and move it to a point perpendicularly above the dot, and draw a straight line down to, and ending in, the dot. The distance above the dot to which the pencil should be moved was 
not designated. The records of the process included everything from the making of the dot to the end of the downward stroke. After a series of ten experiments had been made in this way, the subject was given special instructions each time as to the rate at which he should draw the downward line. Sometimes he was told to draw it slowly, at other times rapidly, and at other times at his natural speed. The instruction changed from experiment to experiment. This enabled the subject to get an introspective comparison between the experiences of drawing at different rates. About ten experiments were made with each of these special instructions, so that in this series there were in all about forty experiments with each subject.

The measurements for accuracy included the length of the line in millimeters, its straightness, and the amount by which it varied from the vertical where there was such variation. Where the line failed to strike the dot the horizontal and vertical distances from the end of the line to the dot were recorded in millimeters. The time measurements included the time consumed in making the dot, the time between the making of the dot and the beginning of the downward line, and the time, for the downward line with the usual minor determinations.

The purpose of this arrangement is to provide a drawing process which shall be as simple as possible. The downward line is now drawn with but one determining purpose-to reach the dot. The experiments with the different subjects will be considered separately.

Subject A.-A. reports a good deal of visual imagery. Attitudes of certainty and clear visual imagery go together. This fact is observed and commented upon by the subject. He said once when he gave his introspections for an uncertain drawing, "I always feel when a line is uncertain that the visual scheme is weak."

The tables in this series give the number of attitudes of certainty and uncertainty reported by the subject in each one of the four parts of the series. They also give the average length, time, and rate of the lines for the cases of certainty and uncertainty respectively. 
TAjLE VII

Subject $A$

No special instruction

$\begin{array}{lcccc}\text { Attitude } & \text { No. } & \text { Length } & \text { Time } & \text { Rate } \\ \text { Certainty } & 4 . & 21.1 & 3.33 & 6.47 \\ \text { Uncertainty } & 6 . & 23 . & 3.19 & 7.35\end{array}$

Special instruction:-Natural speed

$\begin{array}{lcccc}\text { Attitude } & \text { No. } & \text { Length } & \text { Time } & \text { Rate } \\ \text { Certainty } & 3 . & 18.5 & 2.49 & 7.37 \\ \text { Uncertainty } & 6 . & 20.7 & 2.60 & 8.75\end{array}$

Attitude

Certainty

Uncertainty

Attitude

Certainty

Uncertainty:

To attitude

Special instruction :-Slow

$\begin{array}{cccc}\text { No. } & \text { Length } & \text { Time } & \text { Rate } \\ 4 . & 18.9 & 4.20 & +.46 \\ 5 . & 23 .+ & 5.13 & 4.70\end{array}$

Special instruction:-Fast

$\begin{array}{cccc}\text { No. } & \text { Length } & \text { Time } & \text { Rate } \\ 2 . & 16.5 & 1.21 & 13.6 \\ \text { 1. } & 17.0 & 1.30 & 13 . \\ 3 . & 16.6 & .99 & 18.4\end{array}$

This table shows no marked correspondence between attitude and length, or between attitude and time. If one rate-either fast or slow-were especially favorable for the appearance of certainty we should expect a larger percentage of attitudes of certainty in the experiments in which the instruction to draw at that rate was given. In general the certain drawings are drawn at a somewhat slower rate than the uncertain ones. The special instructions do not greatly affect the relative number of attitudes of certainty and uncertainty which appear. In the fast series when the rate becomes very fast no attitude appears.

As for the accuracy with which the subject carried out his task, the measure for this is given in the average horizontal and vertical errors. The horizontal error is the distance from the dot to the downward line, and the vertical error the vertical distance between the end of the line and the level of the dot. The average errors for all cases of certainty and all cases of uncertainty are as follows:

$\begin{array}{lcc} & \text { Horizontal } & \text { Vertical } \\ \text { Certainty } & .8 & 1.9 \\ \text { Uncertainty } & .5 & 3.3\end{array}$

This shows that in cases of certainty, on the average, the end of the line comes nearer to the level of the dot. There is only 
a slight difference in the horizontal error, it being slightly greater for the certain lines.

The pressure records in this series for this subject are very unsatisfactory, because he drew with such very light pressure that in many cases the rise in the curve was barely perceptible. No correlation is possible, therefore, between certainty and a definite type or amount of pressure. One experiment in this series, however, is especially interesting. In one drawing the subject was instructed to draw at the rate which would give him most certainty and "exert a little more pressure." The result was that the subject, following these instructions, drew with great certainty. He pronounced it "as good certainty as I've had."

In general, however, we cannot draw any conclusions from this series with this subject except the one derived from the introspections, that an attitude of certainty is always accompanied by a clear visual image.

Subject $C$.-With $C$. the introspections are quite different in character. He relies mainly upon kinaesthetic factors to guide him in the drawing process. Table VIII follows the plan of the preceding table.

\section{TABLE VIII}

Subject C

\begin{tabular}{|c|c|c|c|c|}
\hline \multicolumn{5}{|c|}{ No special instructions } \\
\hline Attitude & No. & Length & Time & Rate \\
\hline Certainty & Io & 18.9 & 2.60 & 7.0 \\
\hline Uncertainty & 0 & - & - & - \\
\hline \multicolumn{5}{|c|}{ Special instruction:-Natural speed } \\
\hline Attitude & No. & Length & Time & Rate \\
\hline Certainty & 6 & $\mathbf{I} 6.8$ & 2.03 & 8.3 \\
\hline Uncertainty & 0 & - & - & - \\
\hline No attitude & I & I8. & 1.52 & I I.8 \\
\hline \multicolumn{5}{|c|}{ Special instruction:--Slow } \\
\hline Attitude & No. & Length & Time & Rate \\
\hline $\begin{array}{l}\text { Certainty } \\
\text { Uncertainty }\end{array}$ & $\begin{array}{l}2 \\
8\end{array}$ & $\begin{array}{l}13.5 \\
15.8\end{array}$ & $\begin{array}{l}4.04 \\
6.46\end{array}$ & $\begin{array}{l}3.33 \\
2.52\end{array}$ \\
\hline \multicolumn{5}{|c|}{ Special instruction:-Fast } \\
\hline Attitude & No. & Length & Time & Rate \\
\hline $\begin{array}{l}\text { Certainty } \\
\text { Uncertainty }\end{array}$ & $\begin{array}{l}9 \\
I\end{array}$ & $\begin{array}{l}19 . \\
17 .\end{array}$ & $\begin{array}{r}\text { I.I. } 3 \\
.65\end{array}$ & $\begin{array}{l}18.6 \\
26.1\end{array}$ \\
\hline
\end{tabular}


It is apparent at once from these tables that with this subject the rate of drawing has a decided influence upon the attitudes of certainty. His normal rate, as shown by the drawings made with no special instructions, is accompanied by certainty in every case. In the experiments with special instructions the ones in which he is instructed to draw at natural rate are faster than those in which no special instructions are given. In the experiments with the instruction to draw slowly the drawing is made very slowly, except in two cases in which the subject reported that he had forgotten the instruction. Great uncertainty was reported throughout these drawings, except in the two cases in which the instructions had been forgotten. The instruction to draw fast increases certainty. The fast drawings are all called particularly certain by the subject-more so even than those made with no special instructions. Only one drawing in this series shows a trace of uncertainty. This is the fastest of all the fast drawings, and we shall have occasion to refer to it again when we consider the pressure records.

The horizontal and vertical errors for the different series are as follows:

$\begin{array}{lcc} & \text { Horizontal } & \text { Vertical } \\ \text { No special instruction } & \text { I.35 } & \text { I.3 } \\ \text { Instruction-Natural Speed } & .60 & .8 \\ \text { Instruction-Slow } & \text { I.20 } & .3 .5 \\ \text { Instruction-Fast } & 1.25 & .85\end{array}$

The smaller error in the Natural speed series may be attributed to practice, since these were made after the drawings with no special instructions. The slow series in which all but one of the cases of uncertainty occur, shows a large vertical error, and so a correlation between uncertainty and inaccuracy. The inaccuracy is due to the fact that the subject stops drawing before he has come down to the level of the dot. In his introspections he says in one place that "in the slow drawings the length of the line seems greater." Evidently, then, when he draws slowly he overestimates the length of the line he is drawing.

The lines drawn with no special instructions were all certain, and their pressure curves all conform to a fixed type. This curve rises slowly and then shoots up to form a plateau at the end. 
This type of curve was found to go with an attitude of certainty when the triangle was used as a model and the last stroke was a downward one. A typical example is given in Fig. 9, No. I.

1.

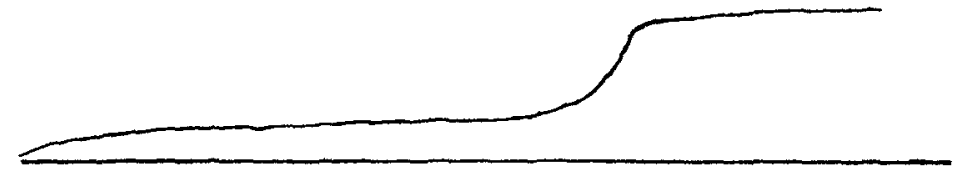

2.

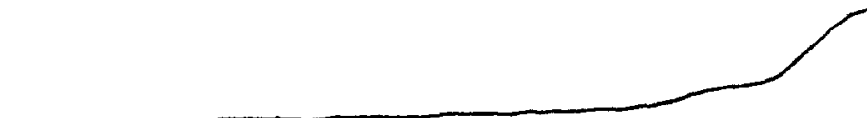

3.
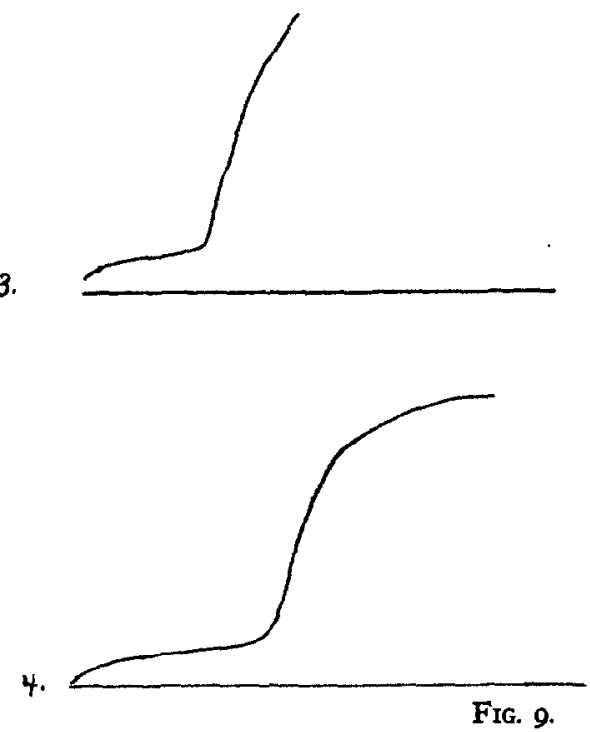

In the series with the special instructions to draw at natural speed, the curve continues to show the certainty type in three of the seven cases, but in four cases it is different. The curves of these four cases are like each other, however, and one of them is illustrated in Fig. 9, No. 2. The introspections do not show that the drawings for which these are the records are markedly different from the others except that they are somewhat less 
certain. In one case certainty was reported. In another there was no attitude. In a third, certainty was reported, but it was called less in degree than that of the previous experiment, the curve of which had a plateau. In the fourth case the subject said that the line had run out of true about half-way down, but had come back, negative certainty giving way to positive.

The curves for the slow drawings may be briefly dealt with. The pressure is very slight in every case, and the plateau at the end is present in only one case. Even here it is so slight as to be scarcely noticeable. So we find that the following out of the special instruction to draw slowly has affected not only the attitude of certainty with which the drawing is made, but also the amount of pressure exerted and the form of the curve.

In the fast drawings the typical certainty curve is present in all but two cases. The curve in these cases is more like the varying form that was observed in the series with the special instruction to draw at natural speed. One of these is the drawing referred to above as the fastest of all the fast drawings-the only case of uncertainty outside the slow series. This pressure curve is shown in Fig. 9, No. 3. No. 4 shows a typical curve from the fast series.

So we find with this subject that the attitude he reports varies with the rate of drawing, and the type of pressure curve varies with the attitude.

Subject F.-In this series F. reports both types of imagery, visual-motor imagery being most prominent. With him the experiment is the same as with the other subjects and the table follows the same plan.

TABLE IX

Subject F.

No special instructions

$\begin{array}{lcccc}\text { Attitude } & \text { No. } & \text { Length } & \text { Time } & \text { Rate } \\ \text { Certainty } & 6 & \text { I5.4 } & 3.31 & 4.98 \\ \text { Uncertainty } & 4 & \text { I4.5 } & 3.14 & 4.80\end{array}$

Special instruction:-Natural speed

Attitude

Certainty

Uncertainty

No.

Length

Time

Rate

4

20.2

I8.7

2.83

3.66 


\begin{tabular}{|c|c|c|c|c|}
\hline \multicolumn{5}{|c|}{ Special instruction:-Slow } \\
\hline Attitude & No. & Length & Time & Rate \\
\hline Certainty & 5 & 20 & $5.5 \mathrm{I}$ & 3.75 \\
\hline Uncertainty & 3 & $2 \mathrm{I}$ & 5.31 & 4.04 \\
\hline No attitude & 2 & 20 & 5.25 & 3.85 \\
\hline \multicolumn{5}{|c|}{ Special instruction :-Fast } \\
\hline Attitude & No. & Length & Time & Rate \\
\hline Certainty & 8 & 20 & 1.29 & 16.3 \\
\hline Uncertainty & 2 & 19 & 1.64 & 14.5 \\
\hline
\end{tabular}

These tables show that the subject was not as much affected by the special instructions as was $C$. The instruction to draw slowly does not result in any marked change in the degree of certainty or in the number of times it is reported. The instruction to draw fast, however, has such an effect, which is to make the series in general more certain. The two uncertain drawings were the first of the series. The subject had a little trouble in getting accustomed to drawing the line fast, and this is reflected in the uncertainty of the first two drawings. After these, however, the series is composed entirely of certain drawings, and the degree of certainty is great.

With this subject the greater average errors are in the certain drawings, so certainty and accuracy in this case do not go together. The average errors are as follows:

$\begin{array}{lcc} & \text { Horizontal } & \text { Vertical } \\ \text { Certainty } & .8 & 2.9 \\ \text { Uncertainty } & .65 & 2.3\end{array}$

The pressure records with this subject show little difference between the certain and uncertain drawings when there are no special instructions, or when the instruction is to draw at natural speed. On the whole the curves of the certain drawings are more regular than those of the uncertain ones, but the difference is not great enough to show a definite type of curve for cerfainty, from which the uncertain curves vary. Six of the ten certain drawings show curves with characteristics similar enough to warrant our calling them all of the same form, but three of the six curves from uncertain drawings follow this form as well. Fig. 10, No. I, illustrates a curve of this type from a certain drawing. When we come to the special instructions "slow" and "fast," however, we find that the certain and uncertain drawings have 
different pressure curves. The curves for the certain drawings conform to the type found in the previous drawings, while the uncertain ones vary from it in some way. In the slow series the curves for the two drawings in which definite uncertainty was reported are very flat, showing very light pressure and very little difference in pressure between the beginning and the end of the line. They are less in amount than any of the certain drawings except one in which "only fair certainty" is reported. Fig. IO

1.

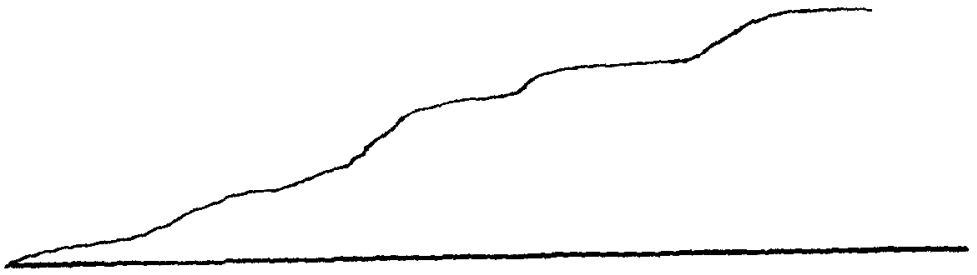

2.

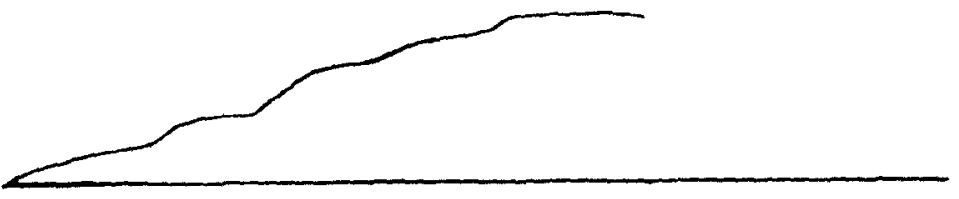

3.

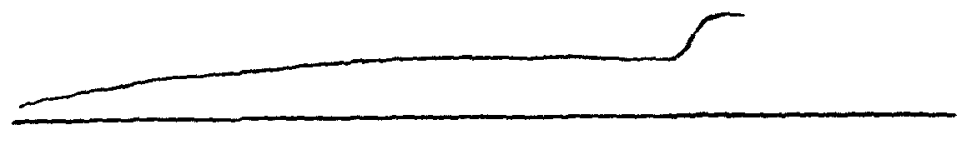

4.

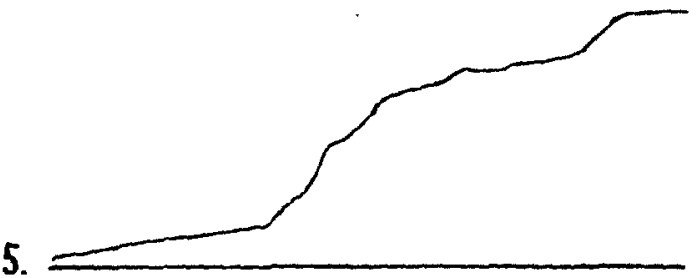

Fig. 10. 
gives in Nos. 2, 3, and 4 respectively, tracings from a certain, an only moderately certain, and an uncertain drawing.

In the drawings with the instruction "fast," certainty was reported in all but the first two cases, in which the subject was becoming accustomed to the process. All the curves of this series except the first two conform to the type already found to accompany certainty. One of them is illustrated in Fig. Io, No. 5 .

With this subject, therefore, we have not been able to correlate the attitudes of certainty and uncertainty with a definite form of curve when the subject has chosen his own rate of drawing, or has been instructed to draw at natural speed. When, however, he has been instructed to draw slowly or at a fast rate, differences in the objective records appear, and these vary with differences in attitude.

Subject R.-R. differs from the other subjects in the amount and kind of imagery he reports. His imagery is chiefly visual, though kinaesthetic imagery sometimes appears. Often incomplete images are reported, and sometimes part of an image is vague while the rest is clear.

TABLE X

Subject $R$.

No special instructions

Attitude

Certainty

Uncertainty

$\begin{array}{cccc}\text { No. } & \text { Length } & \text { Time } & \text { Rate } \\ 7 & 16.4 & \text { 1.98 } & 8.9 \\ 3 & 18.8 & 2.55 & 7.9\end{array}$

Special instruction:-Natural speed

Attitude

Certainty

Uncertainty

$\begin{array}{lccc}\text { No. } & \text { Length } & \text { Time } & \text { Rate } \\ 4 & 17.6 & 2.20 & 8.5 \\ 6 & 15.8 & 2.39 & 6.8\end{array}$

Special instruction:-Slow

Attitude
Certainty
Uncertainty

No.

Length
15.6
15.3

Time

2.72

3.97

Rate

5.86

4. 15

Special instruction:-Fast

$\begin{array}{lcccc}\text { Attitude } & \text { No. } & \text { Length } & \text { Time } & \text { Rate } \\ \text { Certainty } & 7 & 16 . & 1.00 & 15.5 \\ \text { Uncertainty } & 3 & 13.3 & 1.20 & 11.9\end{array}$


These tables show a correlation between the rate of drawing and the character of the attitudes reported. The averages in all four parts of the table show that the certain lines were drawn at a faster rate, and (except with "no special instructions") they are made longer than the uncertain.

The accuracy with which the subject carries out his task seems not to have any effect upon his certainty. A comparison between the average horizontal and vertical errors of the certain and uncertain cases is given in the following table.

$\begin{array}{lcc} & \text { Horizontal } & \text { Vertical } \\ \text { Certainty } & \text { I.I } & 2.3 \\ \text { Uncertainty } & \text { I.8 } & 1.5\end{array}$

Turning now to the pressure curves of this series, we find that in the experiments with no special instruction, and in the ones with the instruction to draw at natural speed, the certain drawings follow a form which is rather like the form of the curve for the certain lines in the experiment with this subject in Series II and IIa. The curves for the uncertain drawings show a smaller amount of pressure, and they vary from the certainty form in other ways. They are little higher at the end than at the beginning, and sometimes show a decrease of pressure within the drawing of the line. Of the eleven cases of certainty all but four have curves of the certainty form. Among the nine cases of uncertainty only one shows a curve of the certainty form. Fig. I I shows in No. I a curve from a certain drawing and in No. 2 one from an uncertain drawing.

In the slow drawings there are three cases of certainty and six of uncertainty. Two of the cases of certainty have curves of the certainty form, the curve for the third is flat. The cases of uncertainty all have flat curves that show no trace of the certainty form. One of these drawings is peculiar, however, in that it is of the usual flat uncertainty type until the very end. Then there is a little sudden increase in pressure. The curve is illustrated in Fig. I I, No. 3. The introspections on this line show that during the drawing it was attended by an attitude of uncertainty, but that at the very end there appeared an attitude of certainty. 
226

JOHN TRUMBULL METCALF

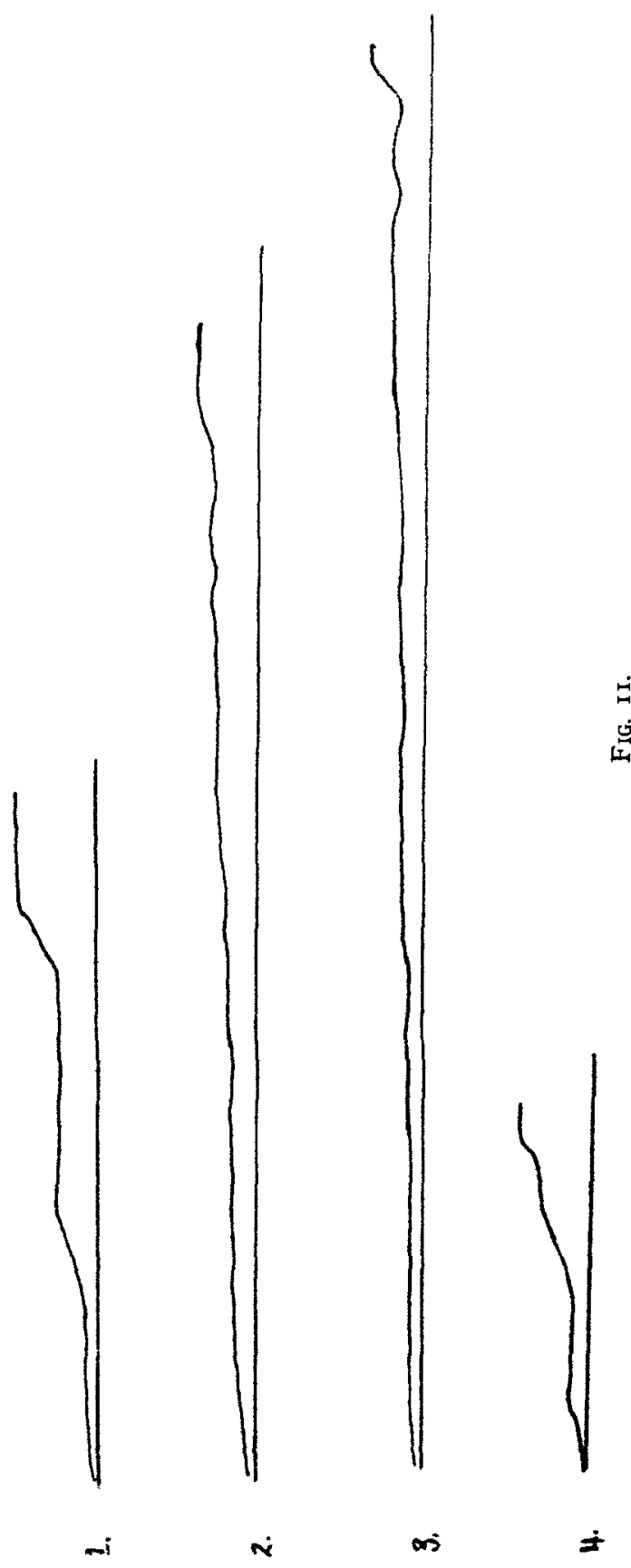


The curves for the fast series are all of the certainty type except four. Two of these are curves for drawings which were called certain in spite of this variation. An example of a certainty curve from a fast drawing is shown in Fig. II, No. 4.

With this subject, therefore, certainty tends again to go with a long line drawn at a fast rate, and a definite type of pressure curve. Uncertainty is correlated, though not perfectly, with a shorter line drawn at a slower rate, and a variation from the type of pressure curve found in the certain drawings. The accuracy with which the subject carries out his task, as measured by the horizontal and vertical errors, seems to have no effect upon the attitude of certainty.

Summarizing the results for Series III for all subjects, we find that there are large individual differences. These appear both in the introspective reports and in the objective records. With A. clear visual imagery and certainty go together. $\mathrm{He}$ is much less influenced as to his attitude by varying rates of drawing than any of the other subjects. Since his pressure records were unsatisfactory it is impossible to compare them with those of the other subjects, but it may be remarked that here as elsewhere he draws with lighter pressure than any of them. C. relies almost entirely upon kinaesthetic factors, and with him rate of drawing has a great influence upon attitude, a slow rate going with uncertainty and a fast rate with certainty. Moreover, with this subject certainty goes with a definite type of pressure curve, and when the attitude is modified with change of rate, this form of curve is modified as well. F.'s imagery is more visual than that of any of the other subjects except A. The correlation between attitude and rate is slightly better with him than with A., but not as good as with the other two subjects. With F. it is not possible to correlate the attitude of certainty with a definite form of curve when he has no special instructions or is instructed to draw at natural speed. When, however, he is drawing at a rate faster or slower than the normal, the attitude of certainty is found to be correlated with a definite type of curve. R. reports less imagery than any of the other subjects. He relies more upon kinaesthetic sensations in drawing than any of the others 
except $\mathrm{C}$. With him there is found a good correlation between length, time, rate, and attitude. The special instructions have more effect upon the relative number of attitudes of certainty and uncertainty reported than in the cases of A. and F., but less effect than in the case of C. With this subject (R.) there is also a fairly good correlation between certainty and a definite type of pressure curve and between uncertainty and some variation from this type.

It is worthy of special comment that the subjects form a series with regard to the completeness of the correlation between attitude and objective records. They also form a series in the imagery they report, and they are ranked in the same order in each series. With the most visual subject the correlation is least complete, and with the least visual and most kinaesthetic subject the correlation is most complete. It seems, then, that with a visualist the attitude of certainty appearing in the course of a drawing is less influenced by the rate of drawing and the pressure exerted than is the attitude of a subject who relies chiefly upon kinaesthetic factors. With the visualist the important thing for an attitude of certainty seems to be a clear visual image, with little or no relevant change in rate and pressure appearing. With the kinaesthetic subject visual imagery has little to do with the attitude which, however, does vary with the rate and pressure characteristics.

\section{SERIES IV AND IVA}

This series, in which all the subjects took part, had for its task the drawing of a simple figure with the left hand. First the drawing was made by the left hand alone (Series IV) and then by the left hand with the right hand drawing symmetrically with it (Series IVa). In this second series the subject took two pencils and made two symmetrical drawings, one with each hand. The figures used are illustrated in Fig. 4, Nos. 6 and 7. The dotted lines in these figures indicate the path followed by the right hand when it drew with the left, though these lines did not appear in the model. The same model, illustrating the drawing to be made by the left hand, was used both when the left hand drew alone and when the right hand drew with it. It was thought 
that these conditions would furnish a good contrast between the attitudes which appeared when the left hand drew alone and when the right hand drew with it. As all the subjects were righthanded, drawing even of the simplest figures with the left hand would be a very unaccustomed activity. On the basis of previous experiments it was thought that the process of carrying out this activity, with left hand alone, would be attended by attitudes of uncertainty. It was thought too that when the right hand drew a symmetrical figure at the same time, the better motor control thus gained for the left would result in greater certainty. The good motor control over symmetrical movements is well known.

Accordingly, a series of the drawings from each of two models was first made with the left hand alone. This series was completed before the series of symmetrical drawings was begun to avoid the practice effect which the symmetrical drawings would have had upon the others if they had been intermingled with them. Then the symmetrical drawings from each of the two models were made. The figures were always made continuously, that is without raising the pencil from the paper. They were begun at the top, and the left hand went first to the left and then downward, or, in the case of the second figure, obliquely to the right. In the symmetrically drawn figures the right hand followed a corresponding inverse course.

In this series the usual accuracy, time, and pressure records were taken. In the symmetrical drawings the time and pressure records were taken of the left-hand drawing only, but the righthand drawing was measured for its accuracy. The symmetrical drawings necessitated a special arrangement of the apparatus. The right-hand drawing had to be made upon a smooth surface exactly beside the left-hand one which was made over the pressure plate. To provide an arrangement which would satisfy these conditions half the opening in the plate, H, Fig. I, was filled up. A piece of zinc the exact size and shape of the right-hand half of the opening was cut out and soldered in place, so that the zinc simply formed a continuation of the original plate. For the right-hand drawings rectangular pieces of paper were cut out 2 convenient size and fixed upon this new portion of the plate. 
In reporting the results of these experiments the model consisting of a horizontal and a vertical line, Fig. 4, No. 6, will be spoken of as the first model, and the one composed of the two slant lines, No. 7, will be called the second model. The lines of the first model are shorter than those of the second. In the first they are $15 \mathrm{~mm}$. long, and in the second $20 \mathrm{~mm}$. The angle is a right angle in each case.

The measurements of accuracy with the first figure included the lengths of the two lines in millimeters, the usual two determinations of their straightness, and the size of the angle in degrees. In the time records the time for each line was measured and the time for the drawing of the whole figure determined. In the second figure the method of measurement was a little different. The length of the two lines was measured in millimeters. There was only one determination of straightness, however. This was the number of slight fluctuations-the general deviation was not measured. The amount by which the two lines vary in direction with regard to each other is contained, however, in the measurement of the angle. The time measurements include the time for each line and the time the pencil is at rest at the apex of the angle between the two lines.

Table XI compares the accuracy records of the two series with the first model. Opposite "IV" are given the averages for the left-hand drawings when they were made with the left hand alone. Opposite "IVa" are given the averages for the left-hand drawings, and opposite "IVa R. H." the averages for the righthand drawings, in the symmetrical series. The lengths of the horizontal and vertical lines are given under " $L$ 'gth $H$ " and "L'gth V" Their straightness error in terms of the number of little deviations under "Str. H" and "Str. V," and their direction or amount of total deviation under " $\mathrm{D} \mathrm{H}$ " and "D V." Under "angle" is given the average size of the angle in degrees. The figures in parentheses are mean variations. 
TABLE XI

Accuracy (First model)

Subject $A$

\begin{tabular}{l|l|l|c|c|c|c|c}
\hline & L'gth.H. & L'gth.V. & Str.H. & Str.V. & D.H. & D.V. & Angle \\
\hline IV & I2.2(2.) & II. (I.5) & 2.5 & 2.7 & I. & 2.2 & I05(3.) \\
IVa & II.4 (1. ) & II.2(.5) & 2.3 & 3. & I.8 & 3. & II2(6.) \\
IVaRH & Io. (1.) & I2. (I.) & I.3 & I.4 & .8 & I.4 & IO2(3.4)
\end{tabular}

Subject C.

\begin{tabular}{l|c|c|c|c|c|c|c}
\hline & L'gth.H. & L'gth.V. & Str.H. & Str.V. & D.H & D.V. & Angle \\
\hline IV & I8.9 (2.3) & I7.4(2.6) & 1.4 & 3.2 & 2. & 2.5 & $90(8)$. \\
IVa & $16.5(2.7)$ & $22 .(3)$. & 2.4 & 2.9 & 1.8 & 3.9 & IOI (9.) \\
IVaRH & I8.5 (2.2) & I8.3(I.4) & 1.3 & 2. & 2.4 & 2.4 & $90(1)$.
\end{tabular}

Subject F.

\begin{tabular}{l|c|c|c|c|c|c|c}
\hline & L'gth.H. & L'gth.V. & Str.H.I Str.V. & D.H. & D.V. & Angle \\
\hline IV & $20.8(1.6)$ & I8.6(2.1) & 3.4 & 25 & 2.6 & 23 & $94(6.7)$ \\
IVa & $15.8(2.7)$ & I5.3(2.9) & 3. & 2.4 & 2. & 3.3 & $107(6.6)$ \\
IVaRH & $14.1(1.9)$ & I5.5(1.8) & I. & 2. & I. & I. & $90(3.7)$
\end{tabular}

Subject R.

\begin{tabular}{l|c|c|c|c|c|c|c|c}
\hline & L'gth.H. & \multicolumn{2}{|c|}{ L'gth.V. } & Str.H.2 & Str.V. & D.H. & D.V. & Angle \\
\hline IV & I6.3 (2.5) & I5.2(1.6) & 2. & 2.7 & I.7 & 2. & $91(4.5)$ \\
IVa & $17.5(2.9)$ & $17.5(3.6)$ & 1.9 & 3.1 & 4.6 & 2.9 & $85(7.5)$ \\
IVaRH & I8. $(2)$. & $20.8(2.9)$ & 1.9 & 2.2 & 2.8 & 4. & $90(3)$. \\
\hline
\end{tabular}

This table shows that the addition of the right hand in the process improves slightly the accuracy with which the subject makes the drawing with his left hand as far as the equality of the lines is concerned, except in the case of $C$. With all the subjects, however, the errors in straightness, direction, and angle are greater when the right hand draws with the left than when the left hand draws alone. The drawing made with the right hand is in general more accurate than either of the drawings made with the left.

Table XII gives the accuracy records for the second model. Under "L'gth. I" and "L'gth. 2" are given the average lengths of the first and second lines. The straightness values for the two lines and the average measurement of the angle follow in the other three columns. Here it will be observed that the addition of the right hand does not have as much effect upon the accuracy of the left-hand drawing as far as the equality in length of the lines is concerned. The straightness of the lines, however, is less in every case when the right hand is drawing with the left. The exactness with which the angle is approximated is not much affected. 
TABLE XII

Accuracy (Second model)

Subject A.

\begin{tabular}{l|c|c|c|c|c}
\hline & L'gth.I. & L'gth.2. & Str.I. & Str.2. & Angle \\
\hline IV & I9. (I.8) & I5. (I.4) & 2.8 & 2.6 & $94.6(48)$ \\
IVa & I7.3 (I.8) & I3.4 (I.2) & 3.5 & 2.2 & $94 .(7)$. \\
IVaRH & I4.5 (I. & I4.7 (2.2) & 2. & I. & IOI. (6.4)
\end{tabular}

Subject C.

\begin{tabular}{l|cc|c|c|c}
\hline & L'gth.I. & L'gth.2. & Str.I. & Str.2. & Angle \\
\hline IV & I9.3 (3.9) & $23 .(3.1)$ & 1.9 & 1.6 & $88 .(6.9)$ \\
Va & I8.3 (1.9) & $20.9(2.7)$ & 2.7 & 1.2 & $90 .(5)$. \\
IVaRH & I4.9(1.1) & I6.I (1.8) & 2.3 & 1.3 & $95 .(4)$.
\end{tabular}

Subject F.

\begin{tabular}{l|c|c|c|c|c}
\hline & L'gth.1. & L'gth.2. & Str.I. & Str.2. & Angle \\
\hline IV & $27.6(3)$. & $23.6(2.8)$ & 2.5 & 1.3 & $94 .(6.8)$ \\
IVa & $24.4(2.2)$ & $22.4(2.4)$ & 5.1 & 4.4 & $84 .(6)$. \\
IVaRH & $19.7(3.4)$ & $15 .(2.5)$ & I.7 & I.7 & I03.(6.)
\end{tabular}

Subject R.

\begin{tabular}{l|c|c|c|c|c}
\hline & L'gth.1. & L'gth.2. & Str.I. & Str.2. & Angle \\
\hline IV & $21 .($ I.8) & $20.6($ I.9) & 2.6 & 3.3 & 100.(10.) \\
Va & $24.4(2.8)$ & $22.6(3.5)$ & 3.9 & 3.5 & $82 .(9.6)$ \\
IVaRH & $22 . \quad(1.2)$ & $21.9(2.3)$ & 2.8 & 1.9 & $93 .(6.6)$
\end{tabular}

The averages for the time records of the drawings made from the first model are given in Table XIII. This table gives under "Horiz." the time for the horizontal line, under "Vert." the time for the vertical line, and under "Total" the time for the whole drawing. The figures in parentheses are mean variations.

TABLE XIII

Time (First model)

Subject A.

\begin{tabular}{l|c|c|c}
\hline & Horiz. & Vert. & 10 al \\
\hline IV & $3.46(.33)$ & $3.02(.52)$ & $6.48(.72)$ \\
IVa & $3.60(.25)$ & $3.26(.43)$ & $6.86(.49)$
\end{tabular}

Subject C.

\begin{tabular}{c|c|c|c}
\hline & Horiz. & Vert. & Total \\
\hline IV & $3.99(.74)$ & $3.46(.66)$ & $7.37(1.35)$ \\
IVa & $3.92(.49)$ & $2.60(.48)$ & $6.52(1.08)$
\end{tabular}

Subject F.

\begin{tabular}{c|c|c|c}
\hline & Horiz. & Vert. & Total \\
\hline IV & $4.02(.65)$ & $3.52(.43)$ & $7.54(1.07)$ \\
IVa & $4.44(.68)$ & $3.81(.56)$ & $8.25(1.13)$
\end{tabular}


Subject R.

\begin{tabular}{l|c|c|c}
\hline & Horiz. & Vert. & Total \\
\hline IV & $2.42(.30)$ & $2.03(.27)$ & $4.45(.52)$ \\
IVa & $3.14(.28)$ & $2.79(.37)$ & $5.93(.59)$
\end{tabular}

This table shows that with all the subjects except $C$. the addition of the right hand results in slower time. With $C$. it results in a faster time. The time records for the second model are given in Table XIV.

$$
\text { TABLE XIV }
$$

Time (Second model)

Subject A.

\begin{tabular}{l|c|c|c|c}
\hline & I. & Point & 2. & Total \\
\hline IV & 3.26 & .50 & 2.61 & 6.37 \\
IVa & 3.55 & .49 & 2.77 & $6.8 \mathrm{I}$
\end{tabular}

Subject C.

\begin{tabular}{c|c|c|c|c}
\hline & I. & Point & 2. & Total \\
\hline IV & 3.67 & 1.47 & 3.34 & 8.48 \\
IVa & 4.00 & I.12 & 3.25 & 8.37
\end{tabular}

Subject F.

\begin{tabular}{c|c|c|c|c}
\hline & 1. & Point & 2. & Total \\
\hline IV & 3.81 & .95 & 3.64 & 8.40 \\
IVa & 4.82 & .69 & 4.54 & 10.05
\end{tabular}

Subject $\mathrm{R}$.

\begin{tabular}{c|c|c|c|c}
\hline & I. & Point & 2. & Total \\
\hline IV & 2.22 & .59 & 2.29 & 5.10 \\
IVa & 2.78 & .49 & 2.42 & 5.69
\end{tabular}

This table shows that the addition of the right hand gives a slower rate of drawing for all subjects except C. With him the rate is slightly faster again.

The introspections, in so far as they have to do with the relative certainty with which the figures are drawn under the two different conditions, give a wholly unexpected result. It appears from them that the addition of the right hand does not increase the subject's certainty with regard to the left-hand drawing, but decreases it instead. The introspections, however, furnish the explanation for this result. All the subjects reported that their attention was for the most part upon the left-hand drawing, but that it would shift over at times to the right-hand one. This 
would occur several times in the course of the drawing of a given figure. It occurred most often in the case of F., who reported that attention oscillated between the two drawings as many as seven or eight times in the course of the process. This shifting of the attention occurred least often in the case of $\mathrm{C}$. He was the only subject who seemed able to keep his attention upon both drawings at once. The time results show that $\mathrm{C}$. was the only subject for whom the addition of the right hand did not result in longer drawing times.

The pressure records may be briefly dealt with. They do not show a different form of curve for each series. The typical form of the record of pressure changes is the same for the subject's left hand whether it is drawing alone or with the right hand drawing at the same time. Thus we have two series, one more certain than the other, yielding pressure curves which do not reflect this difference in attitude. The accuracy records of the two series are little different. The time records do show a difference between the series, for in the case of all the subjects except $C$. the time is somewhat longer for the less certain series. This, however, by itself is not very significant, and for the explanation of these results we must turn to the introspections already mentioned. The addition of the right hand in the drawing process, changing as it does the subject's total reaction, brings about a change in attitude too, and this change is experienced introspectively as a dividing of the attention, or a shift of the attention from the left hand. Thus, although the objective form of the left hand's reaction remains the same (except in its time characteristics), the change in the subject's total reaction has brought about a change in attitude. Introspectively this is designated as distraction of the attention, and it is natural that a slower rate of drawing should be found to accompany it. The case of $\mathrm{C}$. is worthy of special comment. Of the four subjects he was least affected with regard to his attitude of certainty by the addition of the right hand. $\mathrm{He}$ is also the subject who has shown himself throughout to depend most upon kinaesthetic sensations and images. He seems to have had less difficulty than any of the others in adopting the new form of symmetrical draw- 
ing. His time records show that instead of lengthening the time of the drawing, as is the case with the other subjects, the addition of the right hand actually shortened it a little. It appears, then, that the sulject who makes greatest use of kinaesthetic factors is least affected by the change in the form of the total reaction made by the addition of the right hand in the drawing process.

\section{Stmmary and Conclusion}

The purpose of our investigation was to see whether there was a correlation between the conscious attitudes experienced by the subject in connection with his reaction to certain instructions, and the objective form of the reaction as measured by its accuracy, rate, and pressure. We now summarize briefly the results of the experiments.

In the first place, the practice series yields nothing of final value except the indication that the attitude of certainty in some given part of the process may be correlated with a slightly faster rate of drawing.

Series II, IIa and IIb, in which each subject was given a different task, yield results which differ in their definiteness, some of the figures being better suited to the purposes of the experiment than others. With $\mathrm{A}$., who drew the two series of circles, the first anti-clockwise and the second cluckwise, the introspections showed that the second halves of the circles were always less certain than the first halves. The time records show that the rate of drawing increases during the first half and decreases during the second half. The pressure records show that in both series the pressure of the first half rises gradually and regularly with never a decrease. while in the second halves this regular increase is not continued. irregularities occur, and sometimes a decrease in pressure appears. In the anti-clockwise circles a point of maximum uncertainty was located in six of the experiments. This point always came in the third, or between the third and fourth quarters of the circle. The time records show that when it is thus located it comes at the point at which the greatest retardation in rate is taking place, and the pressure records show that at this point too there is a decrease in the amount of pres- 
sure. Thus, in this series for this subject certainty seems to be correlated with an increasing rate of drawing and steadily increasing pressure; uncertainty with a decreasing rate and irregular pressure characteristics.

The triangle figure used in Series II and IIa with C. proved to be very unsatisfactory. The results did, however, give some indication that the attitude of certainty is accompanied by a more regular pressure curve than the attitude of uncertainty. Where the figure ended in a downward stroke (Series IIa) an attitude of certainty was sometimes reported during the drawing of the last line. When so reported the pressure curve of the drawing was found to end in a "plateau."

With F., whose task in Series II and IIa was the drawing of four slant lines combined in two different ways, it is found that in general certainty goes with a longer line and a faster rate of drawing than does uncertainty, and the lines which are mechanically easy for the subject to execute are usually the lines drawn in this way. This, however, does not necessarily hold throughout, because the first line in each drawing is the most certain, although in the first drawing it is mechanically easy and in the second mechanically difficult. This certainty is correlated with a definite form of pressure curve which is followed in the drawing of the first line throughout, and is departed from only in the two cases in which this first line is called uncertain. In the other lines marked contrasts in subjective certainty are reflected in differences in the pressure curves, but small differences are not so reflected.

The most satisfactory figure in Series II and IIa proved to be the four vertical lines which formed the task for $\mathrm{R}$. He was usually able in his introspective report to rank the lines in their order of certainty, and this gave a good basis of comparison with the records of accuracy, time, and pressure. The most certain and least certain lines of each experiment were compared for accuracy and time. It was found that there is practically no difference in accuracy between the most certain and the least certain lines, but the most certain lines are drawn at a somewhat faster rate than the least certain. As for pressure, it is found 
that there is a very definite form of curve which always goes with certainty, and a variation from that form of curve always goes with uncertainty, this variation being greater or less according as the degree of uncertainty is greater or less. In most cases also the curve for the most certain line is between the other two in height, this holding in $80 \%$ of the cases. These results hold both in Series II, in which the lines were drawn downward, and in Series IIa, in which they were drawn upward. Thus, in this series with this subject we find that the accuracy of the drawing has no effect upon the attitude experienced in connection with it. The time, however, is less for the certain than for the uncertain lines, and a definite form of pressure curve is found to go with certainty, and some variation from this form with uncertainty.

In Series III, in which the task was drawing down to a point, the special instructions as to the rate of drawing were given. The subjects are differently affected by these instructions. A. is least affected, and as his pressure records are unsatisfactory very little can be drawn from his results, except that the introspections show that an attitude of certainty is always accompanied by a clear visual image. C. is most affected by the special instructions, the instruction to draw fast resulting in a large increase, and the instruction to draw slowly, resulting in a large decrease in the number of attitudes of certainty reported. The pressure records throughout for this subject show a correlation between certainty and a definite type of curve. With $F$. no noticeable change in the number of attitudes of certainty is brought about by the instruction to draw at a slow rate, but with the instruction to draw at a fast rate the number of attitudes of certainty is increased. This subject draws at a slower rate naturally than any of the others as shown by his records throughout. With this subject no correlation was found between certainty and a definite type of pressure curve in the series in which there were no special instructions and in the series in which the instruction was to draw at natural speed; but in the series in which the special instructions were to draw at a slow or at a fast rate, this correlation was found. With this subject in Series II and IIa it was found that large differences in subjective certainty were reflected 
in the pressure records, but that for small differences no corresponding objective differences could be determined. So also here, it seems that the instructions "slow" and "fast," increasing as they do the subjective differences in attitude, make the objective changes in pressure great enough to be recognized. This subject drew with greater pressure than any of the others, and seemed throughout less sensitive than they to small differences in pressure. The results of this series with $\mathrm{R}$. are quite analogous to those already obtained with him in the previous series. Certainty is found to go with a long line, a fast rate of drawing, and a definite type of pressure curve, and as before with him the accuracy of drawing seems to have no effect upon his certainty. The individual differences exhibited by the subjects in this series are interesting in that they seem to show that persons of different imaginal type are affected in different degrees by the same special instructions.

Series IV gave an unexpected result. It was thought that when the right hand was added in the drawing process greater certainty in the drawing made with the left hand would be the result of the better motor control afforded by the symmetrical movement. It was found that the reverse was the case, the subject reporting less certainty when the right hand drew with the left than when the left hand drew alone. The objective records show that there is little difference in accuracy, and no definite difference in the pressure characteristics between the two series of left-hand drawings. The time records, however, show that the drawings made by the left hand when the right hand is drawing symmetrically with it are made slightly more slowly than when the left hand draws alone, except in the case of C. Thus we find that the only difference in the objective records made by the change in the total form of the reaction which comes with the addition of the right hand is a slight increase in time in the case of three of the four subjects. Nevertheless, the introspective reports betray that with this change in the total form of the reaction there comes a change in attitude in the direction of less certainty. This is described subjectively as a shifting of the attention from one drawing, or one part of the reaction, to the 
other. Thus, with a change in the total reaction we find a change in attitude. Subject C., who was least affected as to his attitude by the change, is also the only subject whose time is not lengthened, and he is the subject who throughout the investigation has been found to use chiefly kinaesthetic imagery. Here again, therefore, we find an instance of imaginal type characterizing the degree of change of attitude under special conditions.

The general result of our investigation is positive. In spite of numerous exceptions and some incomplete records, the results are sufficiently uniform and definite to show that under the conditions of our experiment some objective characteristics of the subject's reaction vary with his introspective attitude. The accuracy of the drawing seems less important than the other characteristics for the appearance of certainty. In some cases greater accuracy and certainty go together, but more often with the same subjects they do not. As for the time factor, certainty is usually found to go with a faster, and especially with an accelerating rate of drawing. Certainty is found also in most cases to be correlated with a definite type of pressure curve, and uncertainty with a variation from this type. In some cases, to be sure, notably with subject $F$., this correlation does not hold between small differences in attitude. but since it holds between large differences, this lack of complete correlation may be attributed to the crudeness of the apparatus which is not sensitive enough to show slight objective changes. In Series IV and IVa we find no appreciable change in the pressure curves of the left-hand drawings -the form of the left hand's reaction is the same in both cases. In this series the difference in subjective reaction is, however, correlated with the difference in the subject's total reaction which is brought about by the introduction of his right hand into the process.

The objective characteristics that we have measured with our apparatus, though they are directly involved in carrying out the instructions, are by no means the only ones that might vary with the changes in subjective attitude. Unconscious eye-movements, incipient movements of the limbs (especially of the arm and hand not used in the drawing), innervations of the larynx, etc., 
might all be part of the subject's reaction to the instructions and might vary with his attitude, just as we have been able to show that certain characteristics of the movements most obviously involved in his reaction vary with changes in attitude. Since it is possible that any of these other motor processes might have been as closely and perhaps more significantly correlated with the attitudes of certainty and uncertainty, the writer hesitates to claim anything final for his results. The investigation is regarded rather as a tentative, exploratory one. The results in his estimation do demonstrate that the conscious attitude is accompanied by relevant objective differences in bodily reaction, and he ventures to express the hope that other investigators will be encouraged to follow up a line of investigation which appeals to him a promising one.

\section{REFERENCES}

I. Freeman, F. N. Preliminary experiments on writing reactions. Psychol. Rev. Monog. Suppl., I907, 8, 30I-309.

2. Judd, C. H. Movement and consciousness. Psychol. Rev. Monog. Suppl., 1905, 7, 199-226. 